\title{
Magnetic Resonance Studies of Brain FunCTION AND NeUROCHEMISTRY
}

\author{
Kâmil Uğurbil ${ }^{1}$, Gregor Adriany ${ }^{1}$, Peter Andersen ${ }^{1}$, Wei \\ Chen ${ }^{1}$, Rolf Gruetter ${ }^{1}$, Xiaoping $\mathrm{Hu}^{1}$, Hellmut Merkle ${ }^{1}$, \\ Dae-Shik Kim ${ }^{1}$, Seong-Gi Kim ${ }^{1}$, John Strupp ${ }^{1}$, Xiao Hong \\ $\mathrm{Zhu}^{1}$, and Seiji Ogawa ${ }^{2}$ \\ ${ }^{I}$ Center for Magnetic Resonance Research, University of Minnesota Medical School, \\ Minneapolis, Minnesota 55455 \\ ${ }^{2}$ Biological Computation Research, Bell Laboratories, Lucent Technologies, Murray Hill, \\ New Jersey 07974
}

Key Words cerebral function, mapping, neurotransmission, spectroscopy, imaging, bioenergetics

Abstract In the short time since its introduction, magnetic resonance imaging (MRI) has rapidly evolved to become an indispensable tool for clinical diagnosis and biomedical research. Recently, this methodology has been successfully used for the acquisition of functional, physiological, and biochemical information in intact systems, particularly in the human body. The ability to map areas of altered neuronal activity in the brain, often referred to as functional magnetic resonance imaging (fMRI), is probably one of the most significant recent achievements that rely on this methodology. This development has permitted the examination of functional specialization in human and animal brains with unprecedented spatial resolution, as demonstrated by mapping at the level of orientation and ocular dominance columns in the visual cortex. These functional imaging studies are complemented by the ability to study neurochemistry using magnetic resonance spectroscopy, allowing the determination of metabolic processes that support neurotransmission and neurotransmission rates themselves.

\section{CONTENTS}

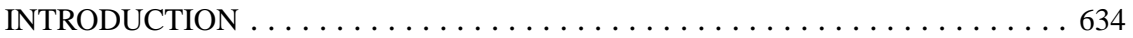

FUNCTIONAL MAGNETIC RESONANCE IMAGING TECHNIQUE . . . . . . . . 635

BLOOD OXYGEN LEVEL-DEPENDENT MECHANISM AND THE

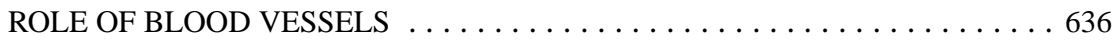

Extravascular Blood Oxygen Level-Dependent Effects . . . . . . . . . . . 636

Intravascular Effect (Blood Contribution to Blood Oxygen

Level-Dependent Contrast) . . . . . . . . . . . . . . . . . . . . . . . . . 639

DEOXYHEMOGLOBIN SIGNALS AND THE ACTUAL SITE OF

NEURONAL ACTIVITY . . . . . . . . . . . . . . . . . . . . . . . . . 642 
SPATIAL SPECIFICITY AND HIGH-RESOLUTION IMAGING . . . . . . . . . . . 644 MAPPING OF HUMAN OCULAR DOMINANCE COLUMNS . . . . . . . . . . . . 646 TIME-RESOLVED FUNCTIONAL MAGNETIC RESONANCE IMAGING . . . . . . 648 MAGNETIC RESONANCE SPECTROSCOPIC DETECTION OF NEUROTRANSMISSION . . . . . . . . . . . . . . . . . 650

\section{INTRODUCTION}

Methods for imaging regions of the brain that have altered neuronal activity, by using nuclear spins of tissue water, were first introduced in 1992 (1-3). This rather unusual development is one of the most recent in a long list of major accomplishments in the relatively short history of nuclear magnetic resonance (NMR). Since its introduction $>50$ years ago (4-6), NMR has rapidly evolved to become an indispensable tool in chemical and biochemical research because it can be used to obtain discrete resonances that are sensitive to the chemical environment. In 1973, the methods to obtain images with magnetic resonance (MR) were introduced (7), leading to the development of magnetic resonance imaging (MRI), which is now solidly established as a research tool and as a noninvasive diagnostic technique in the practice of medicine. A significant portion of research efforts in MRI is focused on the noninvasive acquisition of physiological and biochemical information. The procedure to map brain function, often referred to as functional magnetic resonance imaging (fMRI), is part of this general effort. This development has permitted the examination of functional specialization in the human brain with unprecedented spatial resolution, and it has revolutionized cognitive neurosciences.

The first supporting evidence for the existence of specialization of human brain function was presented by Pierre Paul Broca in the mid-nineteenth century (8). Broca examined a patient who was unable to speak as a result of a stroke but who was otherwise normal. After the patient's death, Broca performed an autopsy and concluded that the seat of the damage was an egg-sized lesion located in the inferior frontal gyrus of the frontal lobe in the left hemisphere and that this region had a unique function in language. This type of functional information can now be acquired much more rapidly and with much greater spatial accuracy by using nuclear spins and MR, which have fueled explosive developments in our investigation of human brain functions. Such neuroscience applications are already too numerous and diverse to include all of them in this review. Instead, we focus on summarizing recent accomplishments and developments that represent the frontier of MR methodology in studies of cerebral function. For example, functional specialization is known to be prevalent at the millimeter to submillimeter scale, a scale of paramount importance in neurosciences because it is closely linked to mechanistic questions regarding information processing. However, until very recently, this scale was not accessible by fMRI. In a recent study, we have demonstrated that such submillimeter neuronal organization in the cat visual cortex can be mapped using ultra-high magnetic fields and fMRI (9). Figure 1 (see color insert) illustrates the "pinwheel-like" distribution map of neurons that 

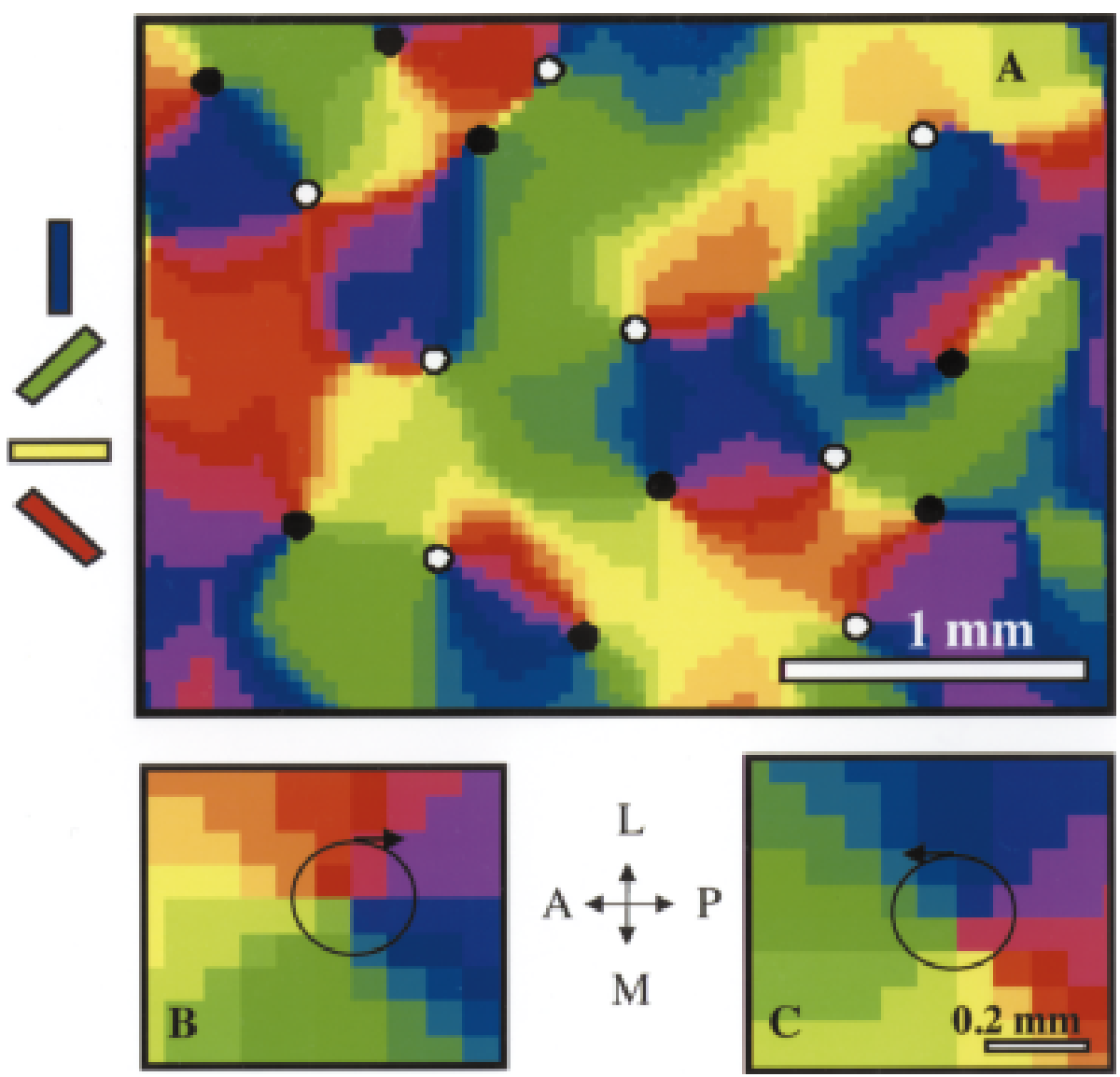

Figure 1 Orientation columns in the cat cortex imaged by early negative blood oxygen leveldependent (BOLD) functional magnetic resonance imaging (fMRI). Shown are composite-angle map and orientation "pinwheels" generated with "negative" BOLD-fMR1 signals during stimulation with moving gratings in different orientations. (A) Composite-angle map obtained through pixel-by-pixel vector addition of the four single iso-orientation maps. The resulting orientation preference at each cortical location is color-coded based on the color key displayed to the left of panel $A$. Tangentially to the cortical surface, the preferred orientations change smoothly, thereby forming a "map" of orientation selectivity. This continuity is interrupted at the "orientation pinwheels," where the cortical columns for different orientations are arranged in a circular manner, thereby forming two types of topological singularities based on their rotational chiralities. White and black circles, clockwise and counterclockwise pinwheels, respectively. Scale bar, $1 \mathrm{~mm}$. (B and $C$ ) Enlargement of two such pinwheels. Circular arrows, The respective directions of change in orientation: A, anterior; P, posterior; M, medial; L, lateral. Scale bars, $200 \mu \mathrm{m}$. Reproduced from Reference 9, with permission of the publisher. 
respond to moving stripes of different orientations, that is, orientation columns or domains. These fMRI maps are identical to those obtained with optical-imaging methods and are discussed in greater detail below. Of course, optical imaging with this spatial resolution is invasive and requires that a section of the skull be removed and the brain exposed. As such, it cannot be used for intact animals and humans.

Understanding how high-resolution maps, such as the one illustrated in Figure 1 (see color insert), can be obtained by fMRI is a crucial question that is still under investigation because fMRI methods do not directly detect electrical activity; rather, they rely on secondary and tertiary metabolic and hemodynamic events that accompany neuronal activity. Numerous issues about these secondary and tertiary processes and how they affect MR signals remain less than fully understood. In this review, we outline some of these issues that are relevant to future accomplishments in MR studies of the brain.

\section{FUNCTIONAL MAGNETIC RESONANCE IMAGING TECHNIQUE}

The most frequently used fMRI method is based on blood oxygen level-dependent (BOLD) contrast, which was first described by Ogawa et al (10-12) in rodent brain studies and was subsequently applied to generate functional images in the human brain (1-3). BOLD contrast originates from the intravoxel magnetic field inhomogeneity induced by paramagnetic deoxyhemoglobin (deoxyHb) that is sequestered in erythrocytes, which are, in turn, compartmentalized within the blood vessels. Magnetic susceptibility differences between the deoxyHb-containing compartments and the surrounding space, which is devoid of this strongly paramagnetic molecule, generate magnetic field gradients across and near the boundaries of these compartments. Therefore, signal intensities in MR images that have been sensitized to BOLD contrast are altered if the regional deoxyHb content is perturbed. This perturbation occurs in the brain because of spatially specific metabolic and hemodynamic responses to enhanced neuronal activity; it has been suggested that cerebral blood flow $(\mathrm{CBF})$ increases while oxygen consumption rate $\left(\mathrm{CMR}_{\mathrm{O} 2}\right)$ in the same area is not elevated commensurably (13-15), resulting in a decreased extraction fraction and lower deoxyHb content per unit volume of brain tissue. Consequently, signal intensity in BOLD-contrast-sensitive images increases in regions of the brain that are engaged by a "task," compared with regions in a resting, basal state.

BOLD contrast relies on the interplay between $\mathrm{CBF}$ and $\mathrm{CMR}_{\mathrm{O} 2}$, as well as cerebral blood volume (CBV). As such, it represents a complex response controlled by several parameters (16-22). MRI techniques, however, can also generate images that are based on measurements of $\mathrm{CBF}$ changes, coupled to neuronal activity (2, 23-27). These CBF techniques rely on tagging the blood spins differentially within and outside a well-defined volume. For example, in the flow-sensitive 
alternating inversion recovery technique (24-26), frequency-selective inversion pulses are used to invert the longitudinal magnetization within a "slab" along one direction (typically axial); in the absence of blood flow, the spins relax back to thermal equilibrium only by spin-lattice relaxation mechanisms that are characterized with the time constant $T_{1}$. If flow is present, however, the relaxation becomes effectively faster as unperturbed spins outside the inverted slab flow in and replenish the net magnetization within the slab. Consequently, the effective spin-lattice relaxation in flow-sensitive alternating inversion recovery, as well as other, similar flow-sensitive techniques $(20,28-31)$, becomes characterized by a shorter time constant, $T_{1}^{*}$, which is related to blood flow. It also follows naturally that if the inversion pulse in flow-sensitive alternating inversion recovery does not define a slab but inverts everything in the whole body (i.e. it is nonselective), blood flow does not enter into the problem at all. Thus, in the flow-sensitive alternating inversion recovery technique, two images are acquired consecutively, each after a fixed delay period following the inversion pulse; in one image, the inversion pulse is slab selective and in the other it is nonselective. The difference image generated from this pair is a flow-sensitive image.

In this review, we focus primarily on the BOLD-contrast-based fMRI. Although CBF-based techniques are less complex mechanistically and can provide quantitative information, they are not commonly used for neuroscience applications because of their inferior contrast-to-noise ratio and inferior speed in volume coverage. Thus, fMRI based on BOLD contrast remains the most commonly and extensively used methodology.

\section{BLOOD OXYGEN LEVEL-DEPENDENT MECHANISM AND THE ROLE OF BLOOD VESSELS}

\section{Extravascular Blood Oxygen Level-Dependent Effects}

If one considers an infinite cylinder as an approximation for a blood vessel with magnetic susceptibility difference $\Delta \chi$, then the magnetic field, expressed in angular frequency, at any point in space, will be perturbed from the applied magnetic field $\omega_{\mathrm{o}}$ (32), where angular frequency $\omega=\gamma B, B$ is the magnetic field, and $\gamma$ is the gyromagnetic ratio $2.6751965 \times 10^{4} \mathrm{rad} \mathrm{s}^{-1} \mathrm{G}^{-1}$ for protons in a spherical water sample. The angular frequency $\omega_{\mathrm{O}}$ corresponding to the applied magnetic field would be $\gamma B_{\mathrm{O}}$. The perturbation is different inside and outside the cylinder and is given by the following equations:

$$
\begin{gathered}
\Delta \omega_{B}^{\text {in }}=2 \pi \Delta \chi_{\mathrm{O}}(1-Y) \omega_{\mathrm{O}}\left[\cos ^{2}(\theta)-1 / 3\right] \\
\Delta \omega_{B}^{\text {out }}=2 \pi \Delta \chi_{\mathrm{O}}(1-Y) \omega_{\mathrm{O}}\left(r_{\mathrm{b}} / r\right)^{2} \sin ^{2}(\theta) \cos (2 \phi)
\end{gathered}
$$

In these equations, $\Delta \chi_{\mathrm{O}}$ is the maximum susceptibility difference expected in the presence of fully deoxygenated blood, $Y$ is the fraction of oxygenated blood 
present, $r_{\mathrm{b}}$ designates the cylinder radius, and $r$ is the distance from the point of interest to the center of the cylinder in the plane that is normal to the cylinder. The angles and the relevant distances are depicted in Figure 2. Note that, outside the cylinder, the magnetic field changes rapidly over a distance comparable with twoor threefold the cylinder radius; at a distance equal to the diameter of the cylinder from the cylinder center, $\Delta \omega_{B}^{\text {out }}$ is already down to $25 \%$ of its value at the cylinder boundary.

We first ignore the blood in the intravascular space (i.e. inside the cylinder) and focus on the extravascular space only. In an fMRI experiment, spins are initially excited and the BOLD phenomenon is allowed to evolve during a delay $T E$, after which the imaging data are collected. If the typical diffusion distances during the $T E$ are comparable with the distances spanned by the magnetic field gradients, then, during this delay, the magnetic field inhomogeneities will be dynamically time-averaged. Typical $T E$ values used in fMRI experiments depend on the field strength (33) and the specifics of the pulse sequence but in general range from $\sim 30$ to $\sim 100 \mathrm{~ms}$. [For optimum contrast, $T E$ must equal $T_{2}$ or $T_{2}^{*}$ in a spin-echo or gradient-recalled echo experiment, respectively (33). $T_{2}^{*}$ and, to a much lesser extent, $T_{2}$ in brain tissue vary with the magnetic field strength.] Thus, blood vessel size compared with the diffusion distances in this $~ 30$ - to 100-ms time domain

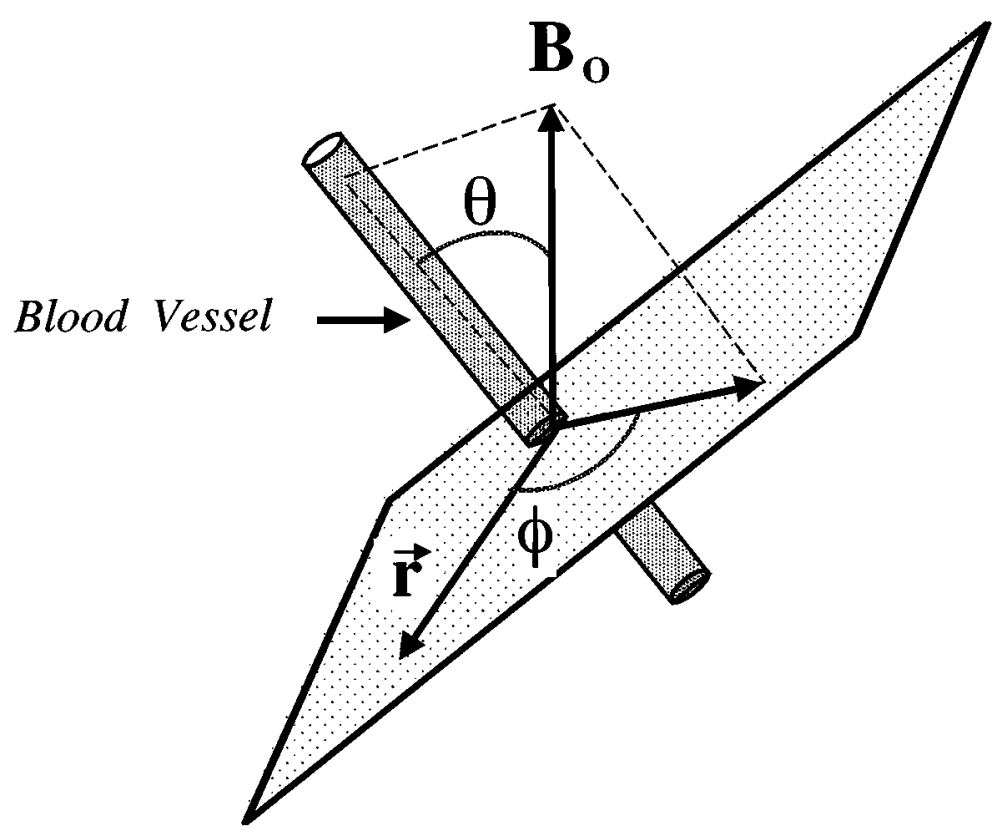

Figure 2 Diagram of a cylinder representing a blood vessel and the parameters that determine magnetic field at points outside the cylinder, when the susceptibilities inside and outside the cylinder are not the same. 
becomes a critical parameter in the BOLD effect (Figure 3). In this time scale, the diffusion distances are such that water molecules dynamically average the magnetic field gradients generated by small blood vessels, for example capillaries, that contain deoxyHb $(16,18,34)$. This dynamic averaging results in signal decay that is characterized by a change in $T_{2}$. Thus, the signal loss from the dynamic averaging is irrecoverable in a spin-echo experiment with a single refocusing pulse in the middle of the $T E$ delay period. Of course, applying many refocusing pulses as in a Carr-Purcell pulse train or applying a large $B_{1}$ field (relative to the magnitude of the magnetic field inhomogeneity) for spin locking during this delay reduces or even eliminates this signal loss caused by dynamic averaging. For BOLD contrast, the exchange that ultimately takes place between intra- and extravascular water across capillary walls can be ignored. The typical lifetime of the water in capillaries exceeds $500 \mathrm{~ms}$ (35-37), which is significantly longer than the typical $T_{2}$ and $T_{2}^{*}$ values in the brain tissue and of the TE used in fMRI studies.

For larger blood vessels, complete dynamic averaging is not possible (Figure 3). Instead, there is partial averaging over a subsection of the volume that is spanned
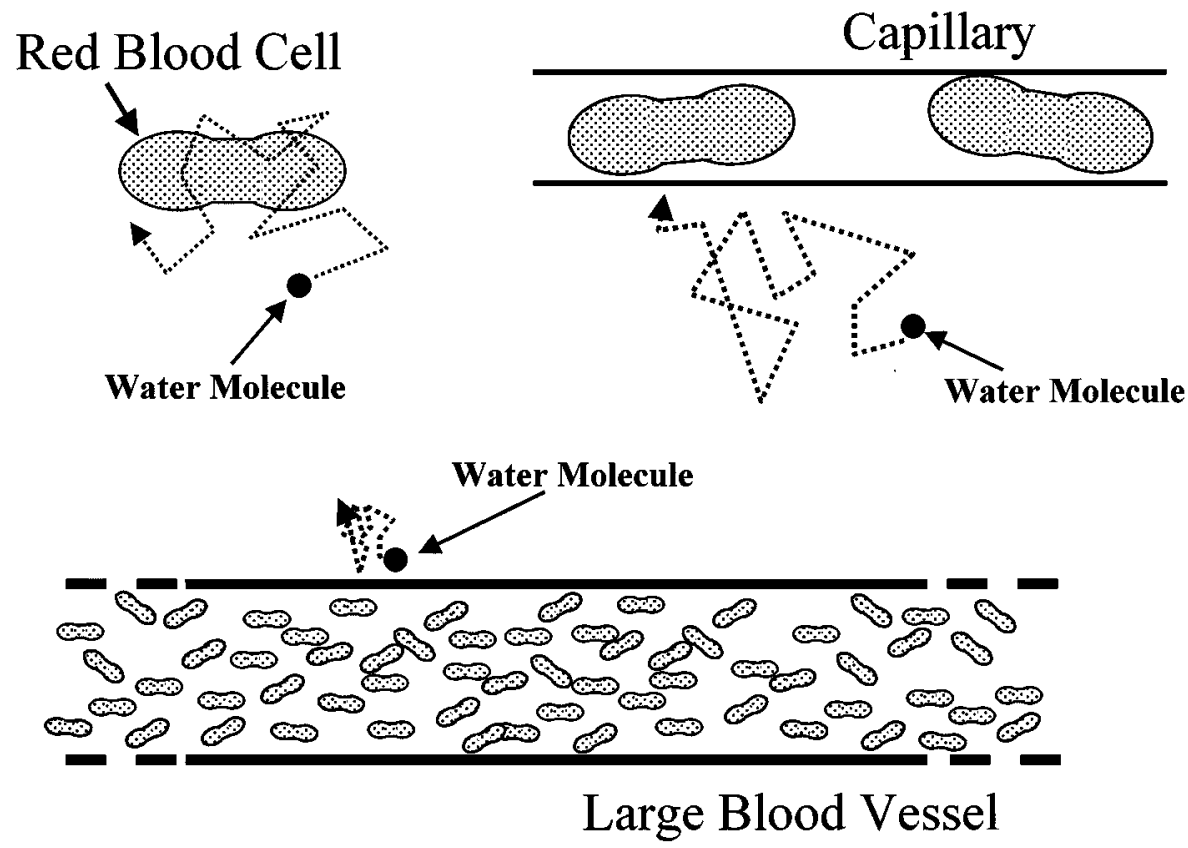

Figure 3 Dynamic- and static-averaging regimens based on diffusion distances compared with the size of the compartment that differs in magnetic susceptibility from the surrounding tissue. The magnetic field gradients are most prominent in the vicinity of the compartments with different susceptibilities, that is, red blood cells, capillaries, and large blood vessels. For the large blood vessels, diffusion distances are not large compared with vessel radius and hence do not lead to complete dynamic averaging. 
by the magnetic field gradients. A water molecule at a given point in space relative to the blood vessel will experience a "locally" time-averaged $\omega_{B}^{\text {out }}$, which will vary with proximity to the large blood vessel. The signal for the entire voxel is the vector sum of these locally averaged magnetization vectors. This sum diminishes in intensity with time as the different local vectors precess at different frequencies and then dephase. This signal loss is called "static averaging" and is reversible after the application of a refocusing radiofrequency pulse. In this domain, if the variation $\omega_{B}^{\text {out }}$ over the voxel is relatively large, signal decay can be approximated with a single exponential time constant $T_{2}^{*}$. This time constant differs from $T_{2}$, which describes irreversible loss of signal intensity under transformation from a refocusing pulse.

Based on the principles discussed above, calculations have shown that the net contribution to transverse relaxation parameters in extravascular BOLD contrast are given by

$$
1 / T_{2}^{*}=\alpha\left(\Delta \chi_{\mathrm{O}} \omega_{\mathrm{O}}\right)(1-Y) \mathrm{b}_{\mathrm{v} \ell}(\text { large vessels })
$$

and

$$
1 / T_{2}^{*}=1 / T_{2}=\eta\left(\Delta \chi_{\mathrm{O}} \omega_{\mathrm{O}}\right)^{2}(1-Y)^{2} \mathrm{~b}_{\mathrm{vs}} p \text { (small vessels) }
$$

where $\alpha$ and $\eta$ are constants, $\omega_{\mathrm{O}}$ is the external magnetic field in frequency units $(\mathrm{rad} / \mathrm{s})\left[\right.$ i.e. $\left.\omega_{\mathrm{O}}=\gamma B_{\mathrm{O}}\right],\left(\Delta \chi_{\mathrm{O}} \omega_{\mathrm{O}}\right)(1-Y)$ is the frequency shift caused by the susceptibility difference between the interior and exterior of the cylinder simulating the deoxyHb-containing blood vessel, $b_{v \ell}$ is the blood volume for large blood vessels (veins and venuoles with a radius $>5 \mu \mathrm{m}$ for $4 \mathrm{~T}$ ), $b_{\mathrm{vs}}$ is the small-vessel blood volume, and $p$ is the fraction of active small vessels [i.e. filled with deoxyHbcontaining erythrocytes (16)]. $b_{v}$ and $b_{v s}$ refer only to components of the CBV that are relevant to the BOLD effect, in other words, to blood volume in which deoxyHb is present. This means capillaries and small postcapillary venuoles $(<5 \mu \mathrm{m}$ in radius, depending on the field strength) for $b_{v s}$, and larger venuoles and veins for $b_{v \ell}$. Volume changes in arterial vessels with little or no deoxyHb content will not affect BOLD contrast. Therefore, caution must be exercised when interpreting results of studies, such as those based on contrast agents (38), that do not distinguish between arterial, capillary, and venous blood volumes. Recent studies, in fact, suggest that blood volume changes are predominantly arterial (39), hence that these changes do not play a significant role in BOLD fMRI.

\section{Intravascular Effect (Blood Contribution to Blood Oxygen Level-Dependent Contrast)}

In the blood, hemoglobin is also compartmentalized within erythrocytes. Thus, when the deoxy form is present, there are field gradients around the red cells. However, because the dimensions are very small compared with diffusion distances, the magnetic field inhomogeneities are dynamically averaged. The dynamic averaging in this case also involves exchange across the erythrocyte membrane, which 
is highly permeable to water. Thus, in the presence of deoxyHb-containing erythrocytes, the $T_{2}$ of blood decreases $(40,41)$. Therefore, even when we neglect the extravascular effect described above, the $T_{2}$ of blood itself changes when the deoxyHb content is altered by elevated neuronal activity, leading to a signal change in a $T_{2}$ - or $T_{2}^{*}$-weighted image. This effect is present wherever the deoxyHb content has changed, which potentially includes both large and small blood vessels.

As indicated by Equations 3 and 4, a CBV increase in vessels that contain deoxyHb results in signal loss in the extravascular BOLD effect. If we focus on the intravascular contribution, however, the consequence of CBV increase can be more complex. Essentially, the ratio of total blood volume (irrespective of deoxyHb content) to tissue volume must be considered. This ratio increases in a given voxel when CBV is elevated during increased neuronal activity. If the blood $T_{2}$ is longer than the tissue $T_{2}$, then the CBV increase leads to a signal increase rather than a decrease, which is always expected from the extravascular BOLD effect. At 1.5 T, human arterial and venous blood $T_{2}$ values are $254 \pm 26 \mathrm{~ms}$ and $181 \pm 23 \mathrm{~ms}$, respectively (42). In comparison, cerebral tissue $T_{2}$ values range from $\sim 70$ to $90 \mathrm{~ms}$ at $1.5 \mathrm{~T}$ (44). [These investigators measured $T_{2}$ values at $1.4 \mathrm{~T}$, which will also be valid for $1.5 \mathrm{~T}$, given the relatively slow variation of $T_{2}$ with magnetic field strength for water in the brain. For example, $T_{2}$ of cortical gray matter is $63 \pm 6.2 \mathrm{~ms}$ at $4 \mathrm{~T}$ (43), compared with $87 \pm 2 \mathrm{~ms}$ reported for $1.4 \mathrm{~T}$ (44)]. Thus, at $1.5 \mathrm{~T}$, a relative increase in CBV should lead to a signal increase in $T_{2}$ - and $T_{2}^{*}$-weighted images. This is altered at high magnetic fields, because the $T_{2}$ of deoxygenated blood decreases much faster than that of gray or white matter tissue. At $9.4 \mathrm{~T}, T_{2}$ is $\sim 7-8 \mathrm{~ms}$ for rat venous blood for $Y$ values in the 0.7-0.8 range and $\sim 30 \mathrm{~ms}$ for arterial blood, while brain tissue $T_{2}$ is $\sim 40 \mathrm{~ms}$ (45). This has significant implications for high-field fMRI studies.

Blood contribution comes into the BOLD phenomenon in a second special way when blood occupies a large fraction of the volume of the voxel, in other words when there exists one or more large blood vessel(s) in the voxel. When deoxyHb is present in the blood, the blood water dynamically averages the gradients surrounding the erythrocytes and behaves as if it encounters a uniform magnetic field given by Equation 1. This behavior differs from that for the magnetic field experienced by the rest of the voxel. In the immediate vicinity of the blood vessel, the magnetic field varies, diminishing with increased distance from the blood vessel and reaching a plateau at a constant-value away from the blood vessel. The lack of sufficient variation in resonance frequency within the voxel most likely prevents the signal modulation from being approximated as exponential decay. For simplicity, we can neglect the gradients near the blood vessel and consider the voxel to be composed of two large-bulk magnetic moments, one associated with blood and the other with the extravascular volume. These magnetic moments precess at slightly different frequencies, dictated by Equation 1; therefore, the signal from the voxel decreases with time as the two moments lose phase coherence. In this scenario, the signal can even oscillate as the phase between the two magnetic moments increases and then decreases. We can refer to this as the type- 2 blood effect in fMRI. When a voxel contains only capillaries, the blood volume is $\sim 2 \%$ (46); hence, the type- 2 
blood effect cannot exist for such a voxel. However, when a large blood vessel or vessels are present in the voxel, blood volume can significantly increase and become comparable with or even greater than the tissue volume in the voxel. If, of course, the voxel is smaller than the blood vessel dimensions and the entire voxel is occupied by blood, then the type- 2 effect does not come into play either.

The type-2 blood effect and the extravascular BOLD effect caused by static averaging share some similarities. Both can be refocused in a symmetric spin echo and thus nullified. Consequently, they are not present in purely $T_{2}$-weighted BOLD-contrast images and functional images derived from them. However, the type-2 blood effect but not the extravascular BOLD effect is eliminated if the blood signal is nullified, either by use of gradients or because of very short $T_{2}$ values attained at high magnetic fields (discussed below). Thus, all blood effects diminish and even disappear at high magnetic fields because the $T_{2}$ of blood gets very short.

The issue of extra- versus intravascular BOLD effects has been experimentally examined using a Stejskal \& Tanner (47) "diffusion weighting" gradient pair. These gradients null the intravascular signals because of a nonuniform flow of blood (e.g. see 48). This effect provides the means to distinguish between intraand extravascular BOLD effects in functional images. Such experiments have been performed at 1.5 and $4 \mathrm{~T}$ on humans. The studies at $1.5 \mathrm{~T}$ have concluded that most of the BOLD-contrast-based signal increase during elevated neuronal activity is eliminated by Stejskal-Tanner gradients, leading to the conclusion that most of the fMRI signal at $1.5 \mathrm{~T}$ arises from intravascular effects $(49,50)$. One can even suggest that this intravascular BOLD effect is predominantly associated with macroscopic blood vessels because it is unlikely that the gradient pulses used can suppress intravascular signals from microscopic blood vessels such as capillaries and small venuoles (51). As previously discussed, the intravascular BOLD effect in functional brain imaging can arise from the change in blood $T_{2}$ or from what we described as the type-2 blood effect. The latter is refocused by symmetric spin echoes and, therefore, can be present only in gradient-recalled echo or asymmetric spin-echo measurements. Given the fact that symmetric spinecho fMRI experiments at $1.5 \mathrm{~T}$ yield very weak effects compared with gradientrecalled-echo studies, the data acquired by suppressing the blood suggest that most of the fMRI signal at $1.5 \mathrm{~T}$ arises from type- 2 blood effects. The same conclusion was reached in high-resolution two-dimensional and three-dimensional gradientrecalled-echo studies of motor cortex activation (52).

At 9.4 T, the effects of the Stejskal-Tanner gradients are totally different. In a $T_{2}$ weighted fMRI study conducted in the rat brain (forepaw stimulation by symmetric spin echo with one $180^{\circ}$ pulse), the fMRI signals and images were not altered from very small to extremely high $b$ values $^{3}(45)$. The $T_{2}$-based BOLD effect can only

${ }^{3}$ The parameter $b$ is defined as $(\gamma G \delta)^{2}(\Delta-\delta / 3)$ where $\gamma$ is the gyromagnetic ratio (rad/s per $\mathrm{G}), G$ is the magnetic field gradient magnitude $(\mathrm{G} / \mathrm{cm}), \delta$ is the duration of the gradient pulse, and $\Delta$ is the separation in time of the onset of the two gradient pulses. In simple isotropic diffusion, the MR signal in the presence of Stejskal-Tanner gradients decays according to $\exp (-b D)$ where $D$ is the diffusion constant. 
come either from blood, owing to a change in the blood $T_{2}$, or from extravascular effects that are associated with capillaries and comparably sized venuoles. The gradient pair suppresses the blood, except possibly in capillaries and postcapillary small venuoles. Therefore, one can conclude that, at this very high magnetic field, there exists a strong and dominant BOLD effect originating from microscopic vessels. This microvascular BOLD effect may have an intravascular component, but this component cannot be the dominant effect, a conclusion that follows from the fact that capillary blood volume is $\sim 2 \%$, whereas the signal changes observed in these $T_{2}$-based fMRI experiments were $8 \%-10 \%$. Thus, most of the effect must arise from extravascular BOLD-contrast associated with the microscopic vessels. This conclusion is consistent with the fact that intravascular effects are a priori not expected to be significant at this field strength owing to the very short $T_{2}$ of venous and even arterial blood (45).

When $T_{2}$-based BOLD-contrast activation studies were performed with spin echoes and at $4-\mathrm{T}$ field strength in the human visual cortex, $\sim 60 \%$ of the "activated" pixels disappeared at small $b$ values, but the remaining pixels persisted as the gradient strength was increased to attain very large $b$ values $(53,54)$. This result suggests that, at $4 \mathrm{~T}$, there are extravascular and/or intravascular BOLD effects associated with microvasculature, but this is not the only contribution.

For a more detailed review of the above described mechanistic questions, also see Ugurbil et al (48).

\section{DEOXYHEMOGLOBIN SIGNALS AND THE ACTUAL SITE OF NEURONAL ACTIVITY}

In fMRI studies, there are two reasons for concern regarding spatial specificity. First is the potential contribution from different-size blood vessels including the large veins; this concern has been discussed in great detail above and is related to the fMRI methodology. The second concern is physiologic in origin and arises from the ambiguity in the spatial specificity of the physiologic and metabolic events that ultimately yield the functional images.

Optical measurements in animal experiments have demonstrated that the onset of task-related activation first results in signal changes, which are interpreted as an increase in deoxyHb content (55-57). This deoxyHb increase is reversed at $\sim 3 \mathrm{~s}$ after task onset and ultimately results in a relatively large decrease in overall deoxyHb content and the deoxyHb/oxyHb ratio. Similar biphasic behavior has recently been reported with direct measurements of blood $\mathrm{pO}_{2}$ (58), indicating that there occurs an early increase in $\mathrm{CMR}_{\mathrm{O} 2}$, which precedes the onset of blood flow enhancement. If $\mathrm{CMR}_{\mathrm{O} 2}$ is elevated by the energy requirements of increased neuronal transmission, $\mathrm{O}_{2}$ extraction and, consequently, the deoxyHb level are also elevated, provided that the blood flow is not enhanced commensurately. In contrast, a $\mathrm{CBF}$ increase alone, without any alterations in $\mathrm{CMR}_{\mathrm{O} 2}$, causes only a decrease in deoxyHb content in the blood; if there is a difference in the response 
times of these two processes, with onset of CBF enhancement lagging behind, the time dependence of deoxyHb content in the "activated" region is biphasic. There could also be a microvascular volume increase that can contribute to an early increase in the deoxyHb content of the brain (59).

Malonek \& Grinvald (56) have argued that the early response (increase in deoxyHb) was spatially more specific and better defined the columnar structure that was examined in the cat visual cortex in that study. In contrast, they suggest that the CBF increase is not as specific, flooding not only the active but also inactive columns and surpassing in spatial extent the actual area of activation by several millimeters. These claims imply that the BOLD effect associated with the hyperoxygenated, high-flow phase during increased neuronal activity will also be spatially nonspecific at the several-millimeter scale, reflecting the spatial distribution of the CBF response.

An early negative response was first detected with MR methods in humans by using a localized-spectroscopy approach, monitoring the signal from a relatively large voxel (60), and subsequently performing imaging studies that involved averaging of data obtained from several subjects (61). Recently, the early negative response was successfully detected with imaging in single subjects (62-67) at $4 \mathrm{~T}$ and, most recently, at $7 \mathrm{~T}$ (68). The presence of this initial response was also observed in 4.7-T fMRI studies conducted in monkeys (69) and the cat visual cortex (9), and the response had a very similar magnitude and time course to those of the human data obtained at 4 and $7 \mathrm{~T}$.

Figure 4 illustrates the time dependence of BOLD-contrast fMRI signal changes and the early negative responses observed in the human visual cortex at $7 \mathrm{~T}$ during and after a brief visual stimulation (68). In this study, $T_{2}^{*}$-weighted, gradientrecalled EPI images were acquired rapidly, covering only a few slices in the visual

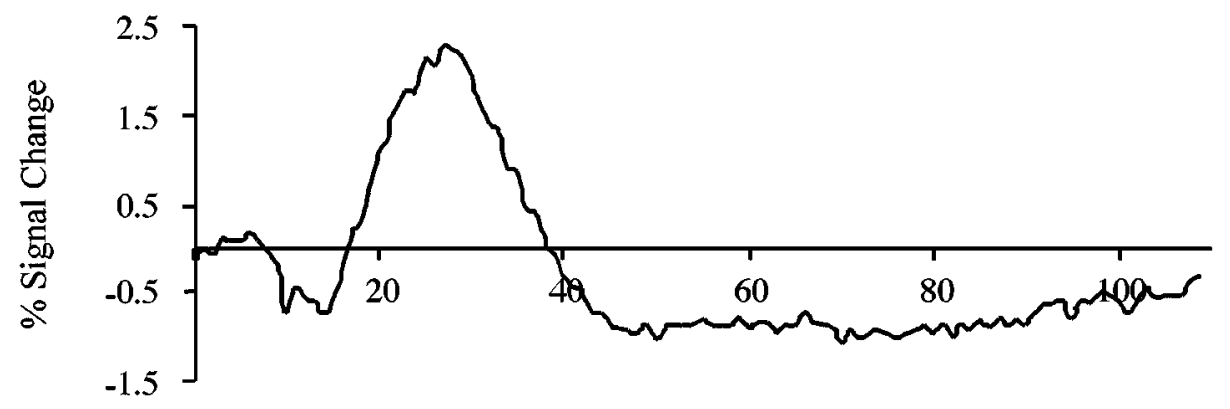

Image Number $(\mathrm{TR}=0.4 \mathrm{~s})$

Figure 4 Signal intensity time course for activated areas in the primary visual cortex obtained at $7 \mathrm{~T}$. Initially the signal decreases, culminating in a valley that is the early negative response or "dip"; subsequently, the signal increases, leading to a peak that corresponds to the positive BOLD. TR, time of repetition. 
cortex, thus sacrificing the spatial extent of coverage and spatial resolution in favor of time resolution. Furthermore, the brief stimuli were repeated 4-10 times, and images were collected in synchrony with the stimulus presentation so that they could be averaged. A signal intensity decrease below baseline was also seen toward the end of the time course (Figure 4); this late-phase, post-stimulation decrease has been observed before, even in the very first fMRI papers, and may reflect a difference in the posttask temporal responses of blood volume (38) and/or a much slower return of $\mathrm{CMR}_{\mathrm{O} 2}$ (70) to basal levels than that of blood flow.

Although the study by $\mathrm{Hu}$ et al (64) demonstrated, for the first time, robust single-subject functional images generated from this early negative response, it did not answer the question of spatial specificity raised by Malonek \& Grinvald (56), because it is difficult to achieve the necessary submillimeter spatial resolution in human fMRI experiments while still detecting the small early negative response, even at a 4-T magnetic field. This resolution may be accomplished at higher magnetic fields, which are just beginning to be used for such studies. The fact that the early negative response was detectable by BOLD-based fMRI, however, is significant both from a mechanistic point of view and for future developments in fMRI.

\section{SPATIAL SPECIFICITY AND HIGH-RESOLUTION IMAGING}

The issue of spatial specificity and resolution of fMRI can also be addressed by using experiments targeted to map functionally distinct neuronal organizations with well-defined topography. Localization is a principle that is widely used in brain research; cytoarchitectonically distinct areas form the basis for functional specialization (71). Such parceling of the cortical tissue into functional subunits is especially prominent at the level of individual cortical columns, where neurons with similar response properties, such as ocular dominance and orientation preference in the visual cortex of mammals, are clustered into columns, spanning the entire cortical plate from the pia to the white matter (72-74). Since the pioneering works by Hubel \& Wiesel (72), the structure, function, and plasticity of cortical columns have been studied by a variety of techniques. Although the use of single and multiunit electrodes provided an ideal tool for assessing the temporal properties of cortical columns, finding a noninvasive technique that can yield comparable fidelity, convenience, and applicability had remained an unsolved problem.

As mentioned above, it was hypothesized that the high blood flow and low deoxyHb state after neuronal stimulation cover a cortical area that is substantially broader than the site of the actual electrical activity $(56,75)$, thus imposing a fundamental limitation to the applicability of conventional BOLD contrast for labeling individual cortical columns. However, the development of early negative BOLD signals in human experiments and the demonstration that analogous signals in invasive optical-imaging studies yield columnar resolution (56) suggested that BOLD fMRI can be used for columnar-level mapping. 
Our group used high-field magnets to obtain MR signals originating from individual orientation columns in cat visual cortex (9). The results of this study indicated that the temporal evolution of the MR signals from the cat visual cortex is biphasic, as in high-field human studies $(64,67$; Figure 4$)$. Stimulation of the animal with moving gratings of different orientations induced a transient decrease of MR signals (the early negative BOLD effect), which was followed by a larger increase in MR signal intensity (the later positive BOLD effect). The spatial coupling between neuronal activity and these two types of hemodynamic responses differed significantly; the initial decrease of BOLD signals accurately yielded individual iso-orientation columns in the cat primary visual cortex, whereas the later occurring, positive BOLD changes were incapable of differentiating between active and inactive columns. This result is in agreement with optical data (57), suggesting that the stimulation of cortical neurons gives rise to a 'biphasic' response, of which only the early increase of local deoxyHb has columnar specificity.

Figure 5 (see color insert) displays patterns of negative BOLD activity in response to two orthogonal orientations (in this case, $45^{\circ}$ and $135^{\circ}$ were used). Analogous to two-deoxyglucose (76) and optical imaging $(57,77,78)$, regions of high activity (i.e. large negative signals) are displayed as dark pixels. It is evident from Figure $5 a$ and $b$ that the iso-orientation columns for orthogonal orientations occupy cortical territories that are complementary. This can be seen more easily in Figure $5 a$, where the positions of iso-orientation columns for $135^{\circ}$ (as displayed in Figure $5 b$ ) are marked with red arrowheads.

Figure $5 c$ and $d$ represent the signal time courses obtained from $45^{\circ}$ and $135^{\circ}$ orientation columns, respectively. Stimulation of the animal with $45^{\circ}$ gratings (Figure 5c) resulted in a transient decrease of MR signals in pixels that represent $45^{\circ}$ columns, whereas no such decrease was observed in $135^{\circ}$ columns. Switching the stimulus orientation to $135^{\circ}$ (Figure $5 d$ ) caused a reversal of the active areas; this time, the $135^{\circ}$ columns produced negative signal changes, whereas the signals from the $45^{\circ}$ columns remained within the range of background fluctuation. The positive signal changes, on the other hand, did not discriminate between $45^{\circ}$ and $135^{\circ}$ columns, because they yielded largely overlapping time courses for both stimulus conditions (Figure $5 c$ and $d$ ).

A characteristic and invariant feature of the mammalian orientation system is the existence of "topological singularities" (77-79) that were observed in a variety of mammalian species by using both multielectrode (79) and optical-imaging $(77,78$, 80-82) techniques. To give rise to such orientation pinwheels, the individual isoorientation columns must be spatially arranged in a highly specific manner that would be extremely difficult to mimic if the underlying columns were not genuine. Figure 1 (see color insert) displays a "composite-angle" map that was obtained through the vector summation of the four individual iso-orientation maps (for $0^{\circ}, 45^{\circ}, 90^{\circ}$, and $135^{\circ}$ ) formed from the initial negative BOLD signal changes. In this composite map, the colors (i.e. preferred orientations) change smoothly, forming a map of orientation selectivity, closely resembling those maps obtained by optical-imaging $(77,78,80-82)$ and multielectrode-recording (79) techniques. 

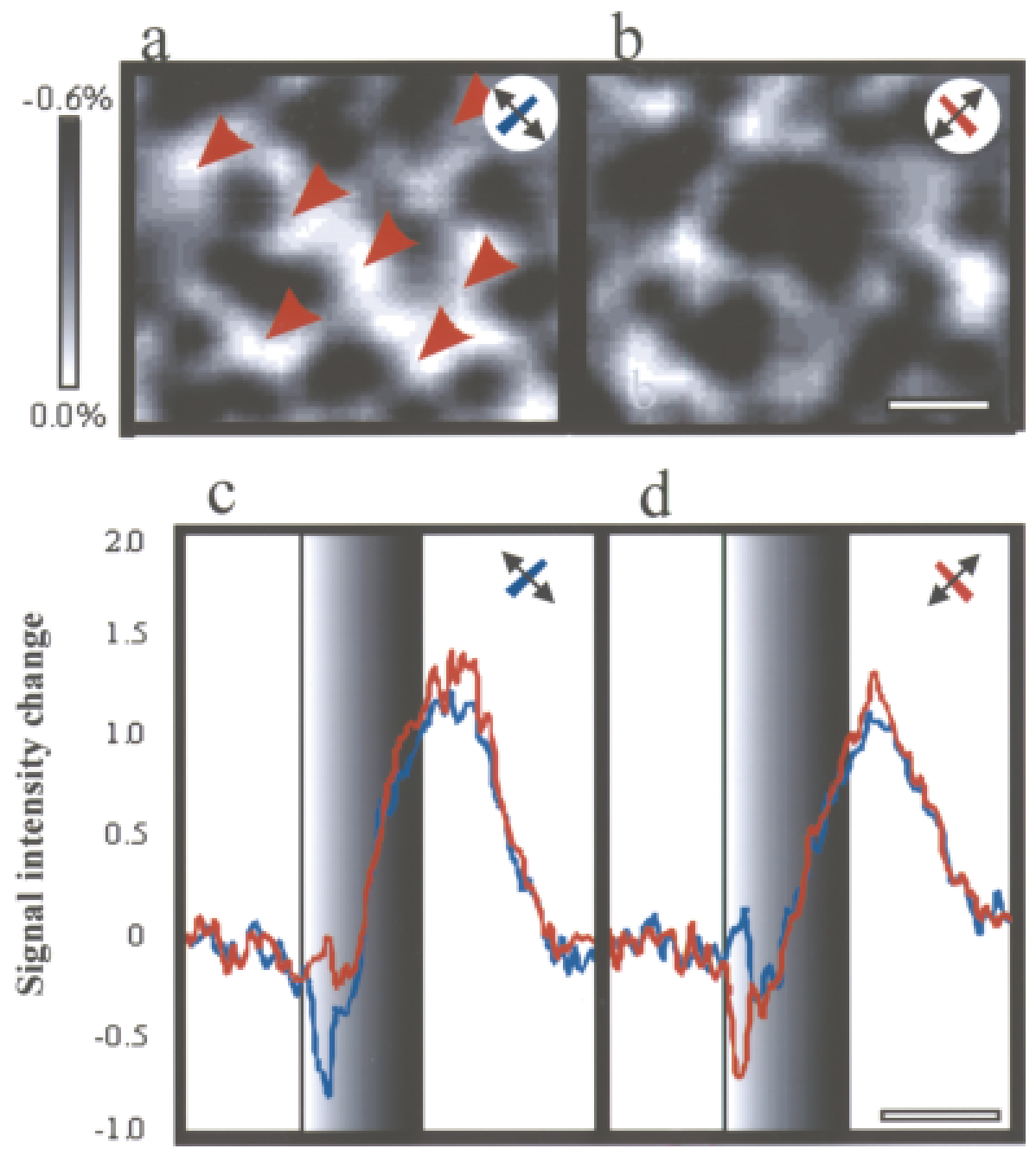

Figure 5 Representation of orthogonal orientations in negative BOLD maps. ( $a$ and $b$ ) Functional maps based on negative signal changes obtained during the stimulation of the animal with $45^{\circ}$ and $135^{\circ}$ orientation, respectively. High negative signals are represented by dark pixels (see text). The domains of high activity in the $135^{\circ}$ map $(b)$ are indicated by red arrows on the $45^{\circ}$ map $(a)$. Panels $(c)$ and $(d)$ display time course associated with regions identified as activated for $45^{\circ}$ (blue trace) and $135^{\circ}$ (red trace) orientations during presentation of $45^{\circ}$ and $135^{\circ}$ orientation gratings. (Reproduced from Reference 9 by permission of the publisher.) 
The continuity of orientation preferences is interrupted only at the singular points where the domains for all orientations converge. Each orientation is represented only once around such a pinwheel, forming two types of topological singularities based on their rotational chiralities. Figure $1 b$ and $c$ display enlarged pictures of such clockwise and counterclockwise pinwheels, respectively. In our study, a pinwheel density of $1.46 \pm 0.17$ pinwheels $/ \mathrm{mm}^{2}(n=4)$ was found, whereas optical-imaging studies yielded average pinwheel densities between $\sim 1.2$ and 1.95 pinwheels $/ \mathrm{mm}^{2}(77,78,80)$. The ratio between clockwise and counterclockwise pinwheels was $\sim 1: 1$ in both fMRI $(1: 0.89, n=4)$ and optical-imaging data [1:0.9 (80)].

\section{MAPPING OF HUMAN OCULAR DOMINANCE COLUMNS}

Left- or right-eye inputs into primary visual cortex V1 are segregated into a system of roughly parallel alternating stripes known as ocular-dominance columns (ODCs), which are $\sim 0.8-1 \mathrm{~mm}$ on a side and 5-10 mm long $(83,84)$. In nonhuman primates and other vertebrates (e.g. cats), the organization of these columns has been studied by histological stains, autoradiography, and microelectrode recordings (e.g. 85-87) and by optical imaging of intrinsic signals $(55,56,88-90)$. In humans, the ODCs have been demonstrated post-mortem in striate cortex by histochemical staining for cytochrome oxidase $(83,84)$ and recently by fMRI.

The above-described orientation column studies in the cat cortex suggest that the early negative BOLD signals are highly specific to the active column whereas the subsequent positive BOLD signals appear in both active and inactive columns. However, it is currently difficult to perform such high-resolution studies with early negative BOLD-contrast techniques in humans. (Sensitivity for a unit volume of voxel size is greater in small-animal studies than in human studies in MRI because small surface coils can be used in the former case. Thus, it is much easier to achieve the necessary resolution to map structures of similar dimensions in small animals than in humans.) In principle, the much larger positive BOLD effect can also be used for columnar-level imaging by using differential mapping. In particular, the optical data demonstrate that, although the CBF response may not be specific at the ODC level (56), a deoxyHb difference across the active and inactive columns is generated, presumably because of the enhanced $\mathrm{CMR}_{\mathrm{O} 2}$ in the active but not in the inactive column (Figure 6).

For human fMRI studies with clinically available hardware, $\sim 3-\mathrm{mm}$ in-plane resolution and $\sim 5-\mathrm{mm}$ slices are typical because of the limited signal-to-noise ratio (SNR) data that are available without extensive data averaging. However, with enhanced SNR data provided by higher magnetic fields (91), it has been possible to demonstrate adjacent image pixels in human V1 that respond primarily to left- or right-eye photic input (92-94). Figure $7 A$ (see color insert) demonstrates a magnified picture of a cortical ribbon along a sulcus in the primary visual 


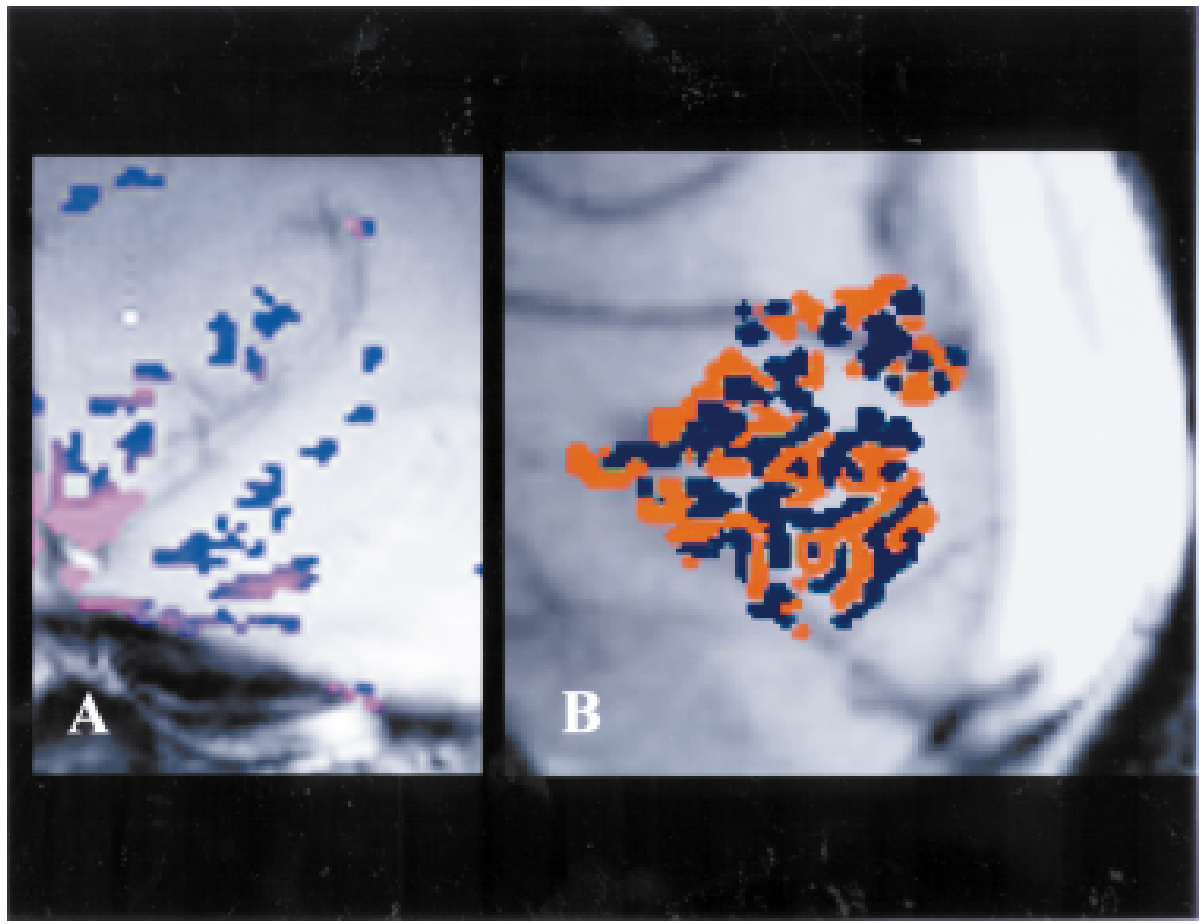

Figure 7 Detection of human ocular-dominance columns (ODCs) during alternating monocular stimulation at $4 \mathrm{~T}$. Image $(A)$ Study obtained on a plane parallel to the calcarine fissure that intersects the ODCs perpendicularly to their long axis. In this view, the ODCs should appear approximately as squares of $1 \mathrm{~mm} \times 1 \mathrm{~mm}$ cross section, separated by $\sim 1 \mathrm{~mm}$. We see a curving sulcus lined by the ODCs (from 92). (B) Sagittal plane adjacent to the interhemispheric fissure, from a more recent study at $4 \mathrm{~T}$ by Menon and colleagues (94) so that the ODCs are visualized as they appear on the cortical surface. The blue and red colors illustrate the columns associated with the two different eyes. 


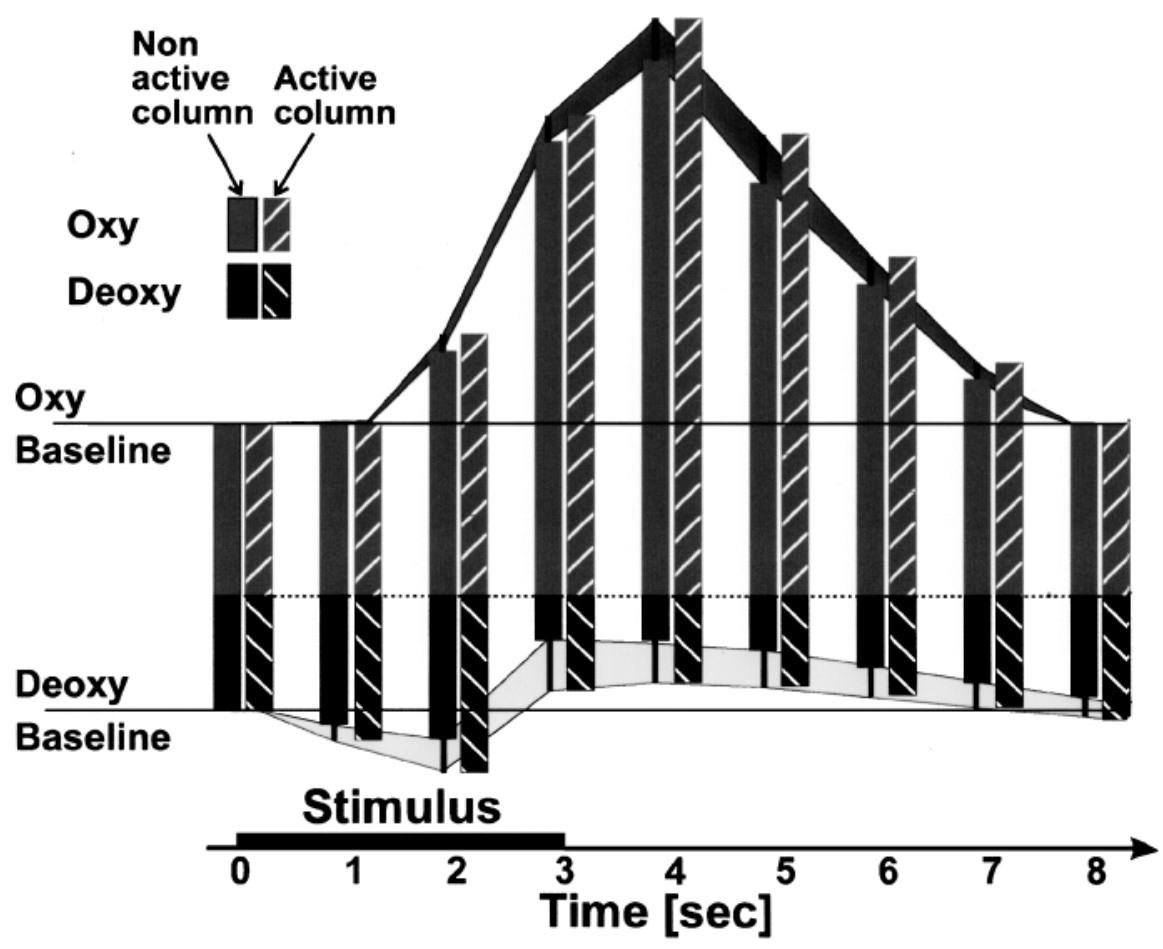

Figure 6 Deoxy- and oxyhemoglobin responses as a function of time during a brief period of visual stimulation in active and inactive columns in the cat visual cortex. The figure summarizes findings by Malonek \& Grinvald (56).

cortex. The image plane is along the calcarine fissure so that columns should appear as $\sim 1 \mathrm{~mm} \times 1 \mathrm{~mm}$ rectangles separated by $\sim 1 \mathrm{~mm}$ in the cortical gray matter.

The paradigm in this study was to use first a binocular stimulation and then alternating left-right monocular stimulation. The data were, however, analyzed by looking for statistically significant differences in pixel intensities for only the monocular-stimulation period, ignoring the binocular stimulation completely. The pixels identified as "activated" during either the left- or right-eye monocular stimulation also showed activation for the binocular period $(92,95)$, as they should if they indeed represent ODCs as opposed to random statistical correlations. Figure $7 B$ (see color insert) demonstrates ODCs in the human brain from a more recent study at $4 \mathrm{~T}$ by Menon and colleagues $(93,94)$. These images are obtained in the sagittal plane adjacent to the interhemispheric fissure so that the ODCs are visualized as they appear on the cortical surface in this region of the visual cortex. The blue and red colors in Figure $7 B$ illustrate the columns associated with the two different eyes. The columns are now seen not in cross section but along their long axis. 
Although the current state of detecting signals from the human ocular-dominance columns represents a major advance, numerous questions remain about these images. Ideally the approaches for mapping the cat orientation columns must be used. This may be possible in the near future with the introduction of ultra-highfield magnets that are capable of human studies.

\section{TIME-RESOLVED FUNCTIONAL MAGNETIC RESONANCE IMAGING}

fMRI is actually a real-time measurement. Single-slice fMRI images can be acquired in tens of milliseconds, which is adequate to monitor neuronal responses. Unfortunately, the temporal response of fMRI signals is dictated by the response of the vascular system, which is characterized by a time constant of seconds (e.g. 64, 96-101). Because of this limitation and because of sensitivity demands, most fMRI experiments rely on a "block" design that averages many repeated executions of the same task. This approach has significant limitations, especially in cognitive sciences. However, there exist numerous tasks and processes that necessarily engage the human brain for prolonged periods. In this temporal domain, signal changes in the fMRI images track the temporal evolution of stimulation or mental-task performance very well, albeit with a shift in time or a delay that lasts several seconds. This capability permits the acquisition of fMRI data that are gated to a particular time point in stimulus onset or instruction-execution sequence. This type of fMRI data collection is referred to as event-related fMRI.

In event-related fMRI, two distinct types of experiments have been performed. Images can be acquired that are gated to the onset of a task and averaged after repeated executions of the same task (102). However, such averaging loses unique information that is associated with each execution of the task; subjects do not perform the same way each time because both brain function and performance are modulated by effects such as learning, alterations in strategy, errors, and habituation.

The second type of experiment is a true single-trial fMRI study, achieved with the use of high magnetic fields, namely $4 \mathrm{~T}(98,99,103-106)$. At least at $4 \mathrm{~T}$, there exists enough sensitivity to monitor fMRI signal evolution in a single execution of a task without averaging over many trials. With this capability, it is then possible to perform many such single-trial executions of a task, not to average them but to store them separately, and subsequently to analyze and correlate the fMRI data with differences in aspect of the subject's performance (e.g. response time, errors, etc). In this way, the hemodynamic response time differences can also be factored out and distinguished from temporal behavior of neuronal activity. Figure 8 shows an example of such a true single-trial study in which individual response times of the subjects were linearly correlated with the duration of activation in the parietal cortex. Each point in this figure represents a single-subject, single-trial data point. An alternative approach to this true single-trial data is to average such single trials, using performance or response criteria and pooling together only those responses that are similar. 


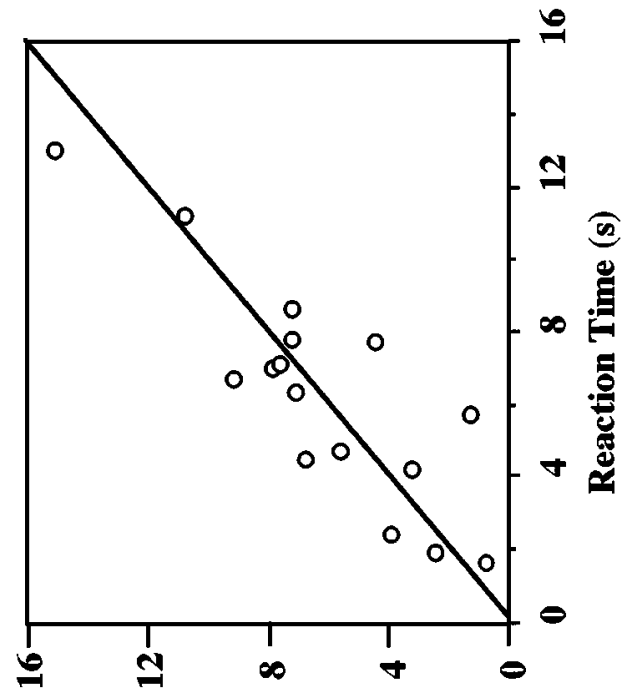

(s) asuodsa. CTOG jo чюp!м paz![вuJоN

$\stackrel{2}{ \pm}$

흐.

鹿寻

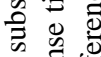

कै

造

के

可.

छ

$\exists$.

胥 एे

\& 0 -

寻专

¿

율 웜

잉

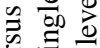

एक

恼

ํํㅇ. 줄

के

as $\frac{0}{00} \frac{0}{0}$

.

ఏ્త

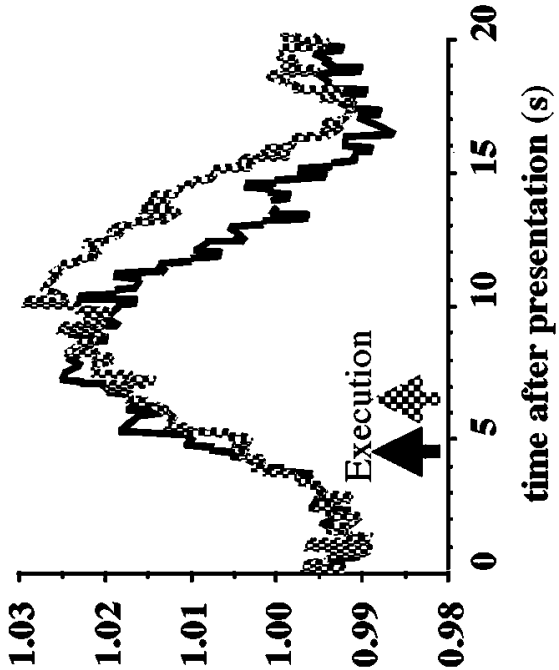

(s!un •qJe) א१!suәqu!
ช

政

클 䒕

के एँ

บ 立

完

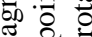

兄

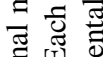

흐 뙤

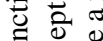

$\Xi$ 닌

$\Xi . \Xi$

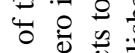

IN

可高

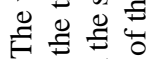

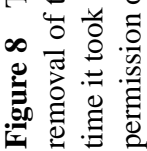


One potential confounding problem with such single-trial fMRI studies is the presence of various types of spatiotemporal patterns in the fMRI signals even under basal resting conditions. $T_{2}^{*}$-weighted MRI signals fluctuate with heartbeat and respiration; such fluctuations can be removed from the fMRI data (e.g. 107112). When cardiac and respiratory fluctuations are suppressed, fMRI signal from the resting human brain still exhibits low-frequency oscillations at $\sim 0.1 \mathrm{~Hz}(112-$ 115). Near-IR (infrared) optical studies also show this slow oscillation. Therefore, techniques that can separate the fMRI data into its various components (e.g. 112) and in the process significantly improve effective SNRs for detection of function will play a crucial role in mapping brain functions, particularly in single-trial fMRI studies with temporal resolution.

\section{MAGNETIC RESONANCE SPECTROSCOPIC DETECTION OF NEUROTRANSMISSION}

In addition to MRI, which uses protons of tissue water, MR plays an increasingly important role in detecting neurochemicals directly and noninvasively in the brain, including the human brain. This capability is based on the sensitivity of the resonance frequency of nuclear spins to their chemical environments (i.e. the chemical-shift effect). This method of acquiring MR data, referred to as MRS, can be performed with spatial localization so that signals can be obtained from a well-defined region in the space.

Spatially localized MRS has been used to measure aspects of brain function and neurotransmission directly. Recent efforts have focused on understanding the coupling between cellular bioenergetics and neuronal activity (e.g. 116-122). The ${ }^{13} \mathrm{C}$ nucleus, the only NMR-detectable, stable carbon isotope that is normally present at $1.1 \%$ abundance, has played an important role in these efforts. If ${ }^{13} \mathrm{C}$ enriched glucose is given to a living organism, the ${ }^{13} \mathrm{C}$ label is incorporated through metabolism into several positions in many different compounds. Of interest is the incorporation of the label into the intermediates of the tricarboxylic-acid cycle, which generates reducing equivalents that are used in oxygen consumption. The label is then transferred into the amino acids glutamate, aspartate, and glutamine. The ability to monitor the labeling of intracellular compounds in intact cells was first demonstrated with Escherichia coli (123). Today, using advanced shimming techniques (124) and three-dimensional localization methods, such highly specific data can be obtained in human and animal brains from relatively small-volume elements (e.g. 116, 120, 125-127).

The human brain ${ }^{13} \mathrm{C}$ spectrum in Figure 9 (obtained at $4 \mathrm{~T}$ in our laboratory) illustrate the detection of many labeled compounds from a relatively small, ${ }^{4}$

\footnotetext{
${ }^{4}$ Because the intracellular compounds detected are in the millimolar range, as opposed to $\sim 100 \mathrm{M} \mathrm{H}$ atoms in tissue water, MRS does not have the millimeter resoluton achieved by MRI, which is based on water signals. Volumes of $\geq 1 \mathrm{~cm}^{3}$ in the human head, and much smaller volumes in animal heads, however, can be used in some studies.
} 


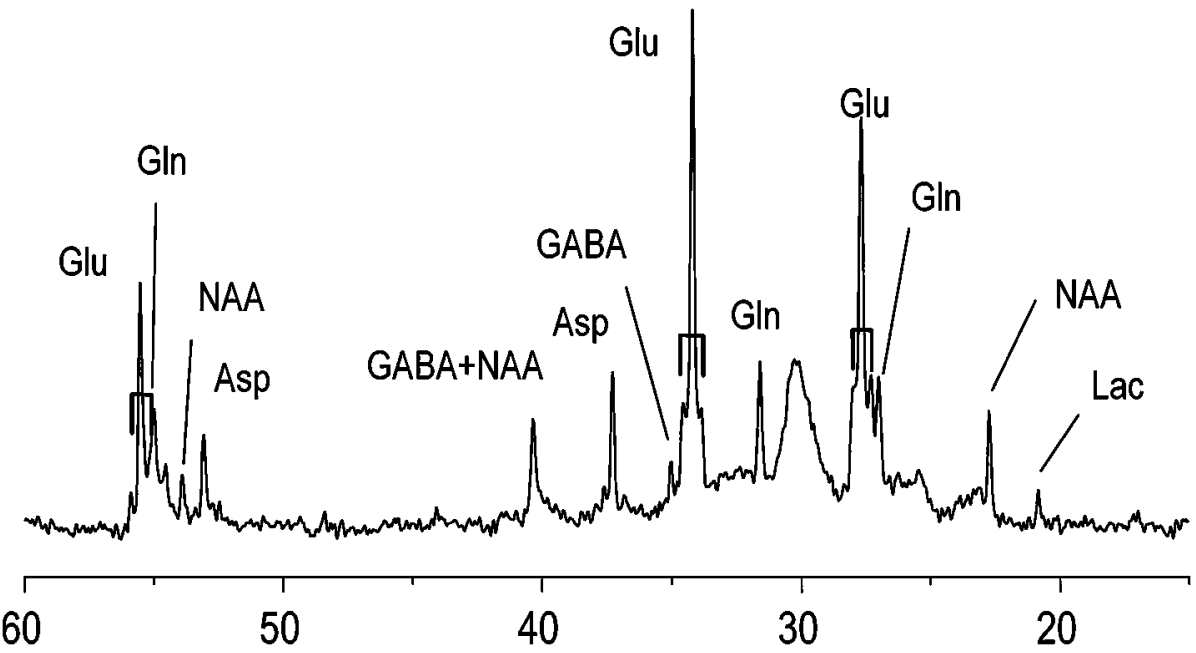

Figure $9{ }^{13} \mathrm{C}$ NMR spectrum acquired from a volume localized in the human visual cortex and obtained at $4 \mathrm{~T}$. Glutaminergic neurotransmission rate and oxygen consumption rate can be calculated from spectra obtained as a function of time. Signals from multiple carbons of various amino acids and neurotransmitters are detected. Asp, aspartate; Gln, glutamine; Glu, glutamate; GABA, $\gamma$-aminobutyric acid; Lac, lactate; NAA, $N$-acetyl aspartate. Republished from Reference 120 by permission of the publisher.

localized region in the visual cortex, and the first-time measurement of neurotransmission rate in the human visual cortex (120). A subsequent effort on humans at $2.1 \mathrm{~T}$ (121) reported basically the same results but used at least threefold-larger volumes (144 ml versus $45 \mathrm{ml}$ ) and longer data acquisition times for signal detection owing to the lower field used. In these studies, it is possible to extract information from the compartmentalized metabolic pathways illustrated in Figure 10. Most important is the glutamate-glutamine cycling between glia and the neurons, the two major cell types that are present in the brain. Glutamate is the major excitatory neurotransmitter. Once it is released into the synaptic cleft and binds the postsynaptic receptors during neurotransmission, it is scavenged rapidly by nearby glial processes $(128,129)$. Glutamate is then converted to glutamine by glutamine-synthase, which is present only in the glia (130); glutamine is subsequently transported to the neurons and converted to glutamate to replenish vesicular glutamate. Thus, glutamine labeling in ${ }^{13} \mathrm{C}$ experiments can, in principle, occur predominantly through glutamate release through neurotransmission and hence reflect the kinetics of neurotransmission.

The proton nucleus has also been extensively used in MRS experiments, either to monitor the subset of MR-visible metabolites or in combination with ${ }^{13} \mathrm{C}$ labeling to detect selectively the ${ }^{13} \mathrm{C}$-labeled compounds during metabolism of ${ }^{13} \mathrm{C}$-labeled glucose infused into the bloodstream. In the first category of applications, probably 


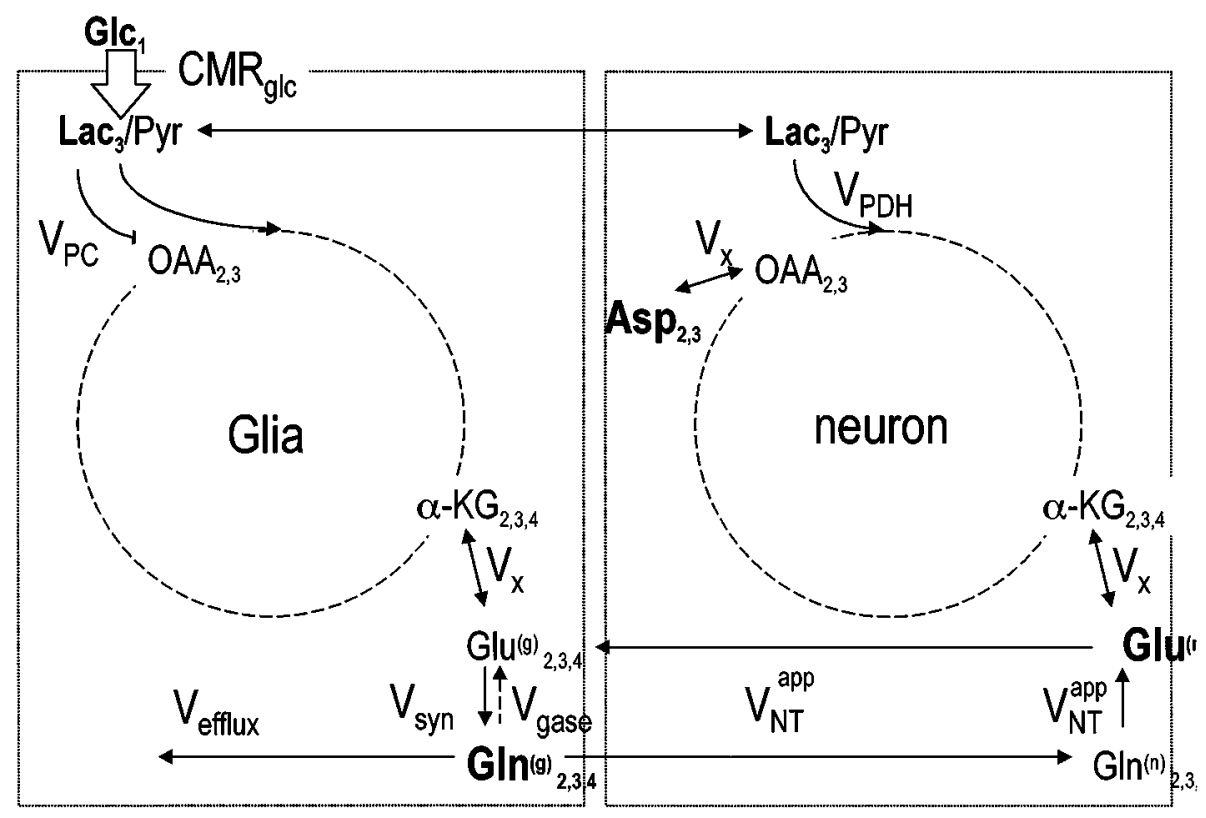

Figure 10 Metabolic pathways in neurons and glia that can be modeled by ${ }^{13} \mathrm{C}$ NMR data. $\mathrm{CMR}_{\mathrm{glc}}$, cerebral metabolic rate of glucose consumption; Glc, glucose; Lac, lactate; Glu, glutamate; Gln, glutamine; Asp, aspartate; $\alpha-\mathrm{KG}$, alpha ketoglutarate; $\mathrm{V}_{\mathrm{PDH}}$, rate of pyruvate dyhydrogenase; $\mathrm{V}_{\mathrm{PC}}$, rate of pyruvate carboxylase; $\mathrm{V}_{\mathrm{NT}}^{\text {app }}$, apparent rate of glutaminergic neurotransmission; Pyr, pyruvate; OAA, oxaloatic acid; $V_{\text {efflux }}$, rate of glutamine efflux or extrusion from the gila. $\mathrm{V}_{\text {syn }}$ and $\mathrm{V}_{\text {gase }}$ define the rate of glutamine synthesis and breakdown from and to glutamate, respectively. $\mathrm{V}_{\mathrm{x}}$ defines the rate of exchange between metabolites indicated in the diagram. Republished from Reference 120 by permission of the publisher.

the most important has been the ability to completely resolve the glucose resonance in the human brain. This has permitted the investigation of glucose transport in the human brain in great detail $(131,132)$. The relevance of these studies arises from the fact that glucose is the major carbon substrate of the brain and its metabolism is related to brain activity.

In the second category of studies, the aim is to take advantage of the greater sensitivity of the proton nucleus while retaining the wealth of chemical information present in ${ }^{13} \mathrm{C}$ spectroscopy. However, because the proton nucleus has a significantly smaller chemical-shift range, obtaining the same chemical information that is available in the ${ }^{13} \mathrm{C}$ measurements has not been possible. Based on the resolution improvements achievable with high magnetic fields and advanced shimming methods (133), this limitation can be alleviated (127). Even with the limited chemical-shift range available at moderately high magnetic fields such as $4 \mathrm{~T}$, however, important studies have been performed that are relevant to the 
issue of coupling of the energy production process to neuronal activity $(117,118$, 122).

It is well known that, under resting conditions, the cerebral metabolic rate of glucose consumption $\left(\mathrm{CMR}_{\mathrm{glc}}\right)$ is well coupled to $\mathrm{CMR}_{\mathrm{O} 2}$ as well as to $\mathrm{CBF}$ in the human brain (134 and references therein), and the glucose metabolism occurs almost completely through oxidation. However, this appears not to be the case during increased neuronal activity. Based on positron emission tomography (PET) studies, the increases of $\mathrm{CMR}_{\mathrm{O} 2}(0 \%-5 \%)$ were found to be much less than the elevation in $\mathrm{CBF}$ and $\mathrm{CMR}_{\mathrm{glc}}(40 \%-51 \%)$ during visual and somatosensory stimulations $(13,15)$. This early PET result is still highly debated, and the intensity of debate has increased recently in view of its significance in understanding the BOLD response that has come to play such a prominent role in neuroscience research. The difficulties and complexities associated with PET measurement of $\mathrm{CMR}_{\mathrm{O} 2}$ have also led to skepticism about the validity of the data that generated this controversial concept.

Resolution of this problem requires new studies, especially using techniques that avoid PET-specific errors. Measurements in a single subject within a single experiment are also crucial to avoid large variances that are generated by intersubject averaging. This was recently accomplished in the human brain by using the isotopic turnover rate of glutamate $(\mathrm{Glu})$ from infused $\left[1-{ }^{13} \mathrm{C}\right]$ glucose and indirect detection through coupled protons. Glutamate-labeling kinetics were monitored for activated and resting states simultaneously in the same individual during hemifield visual stimulation, by acquiring data in two distinct small volumes that span the primary visual cortex (122). Hemifield visual stimulation selectively activates the primary visual cortex of the contralateral hemisphere, comprising approximately half of the primary visual cortex volume that normally would be engaged during full-field stimulation. Spectra were acquired from two volumes positioned so that only one of the two covered the activated region within one hemisphere, whereas the other covered the analogous but nonactivated region within the other hemisphere. Figure 11 (see color insert) is an image that shows the activation in one hemisphere, the location of the spectroscopic voxels, and the time courses of glutamate labeling from the activated and control voxels. These data put an upper limit on the increase in $\mathrm{CMR}_{\mathrm{O} 2}$ of $30 \%$ versus larger increases in $\mathrm{CBF}$, supporting the concept that $\mathrm{CMR}_{\mathrm{O} 2}$ is not stochiometrically coupled to increases in $\mathrm{CBF}$ and $\mathrm{CMR}_{\mathrm{glu}}$.

\section{ACKNOWLEDGMENTS}

The work performed at the University of Minnesota was supported by NIH grants RR08079 [a National Centers for Research Resources (NCRR) grant], RR00400, NS38295, NS35192, NS32919, NS38070, NS39043, MH57180, MH55346, MH59245, and CA76535 and by the Whitaker Foundation and the Keck Foundation. 


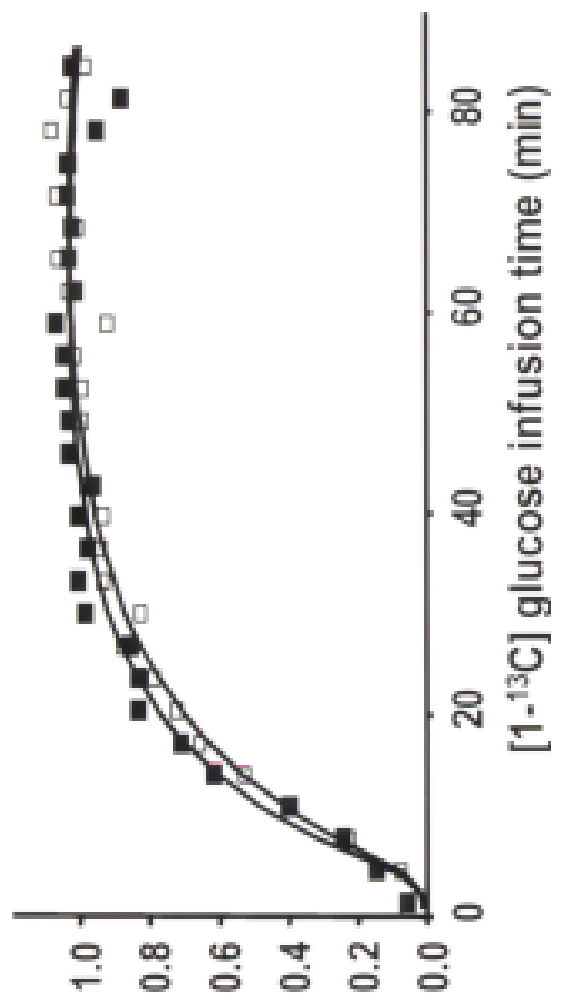

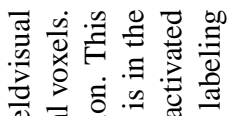

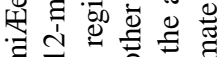

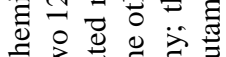
ob 急 不

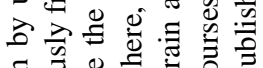
春

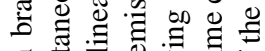

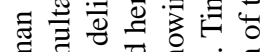

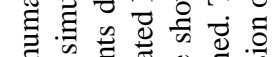

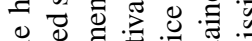

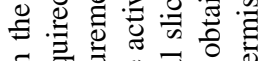
ప ప్ర 纯 సี

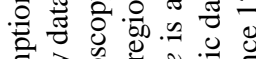
ते ๑ ర 8 ० क 2 ? 2 बิ रेक $\cong . \Xi$ क 造造 氜

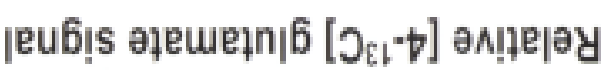

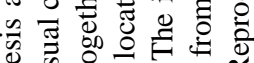

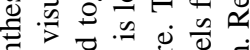

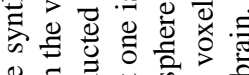
芯 苞过

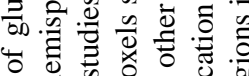
Ч (1) ฮ ¿

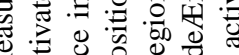
ఏ 巳 그욣

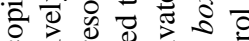
రి. 式苍 论

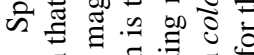

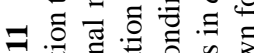

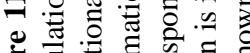

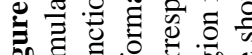

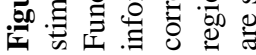




\section{Visit the Annual Reviews home page at www.AnnualReviews.org}

\section{LITERATURE CITED}

1. Bandettini PA, Wong EC, Hinks RS, Tikofsky RS, Hyde JS. 1992. Time course EPI of human brain function during task activation. Magn. Reson. Med. 25(2):390-97

2. Kwong KK, Belliveau JW, Chesler DA, Goldberg IE, Weisskoff RM, et al. 1992. Dynamic magnetic resonance imaging of human brain activity during primary sensory stimulation. Proc. Natl. Acad. Sci. USA 89(12):5675-79

3. Ogawa S, Tank DW, Menon R, Ellermann JM, Kim S-G, et al. 1992. Intrinsic signal changes accompanying sensory stimulation: functional brain mapping with magnetic resonance imaging. Proc. Natl. Acad. Sci. USA 89(13):5951-55

4. Millman S, Rabi II, Zacharias JR, Kusch P. 1938. Nuclear moments of Indium. Phys. Rev. 53:384-91

5. Rabi II, Millman S, Kusch P. 1939. The molecular beam resonance method for measuring nuclear magnetic moments. Phys. Rev. 55:526-35

6. Purcell EM, Torrey HC, Pound RV. 1945. Resonance absorption by nuclear magnetic moments in a solid. Phys. Rev. 69:37-38

7. Lauterbur PC. 1973. Image formation by induced local interaction: examples employing nuclear magnetic resonance. $\mathrm{Na}$ ture 241:190-91

8. Broca PP. 1861. Pertre de la parole, ramollisement chronique et destruction particelle du lobe antérieure gauche du cerveau. Bull. Soc. Anthropol. 2:235-38

9. Kim D-S, Duong T, Kim S-G. 2000. Highresolution mapping of iso-orientation columns by fMRI. Nat. Neurosci. 3:16469

10. Ogawa S, Lee T-M, Kay AR, Tank DW. 1990. Brain magnetic resonance imaging with contrast dependent on blood oxygenation. Proc. Natl. Acad. Sci. USA 87:986872
11. Ogawa S, Lee T-M, Nayak AS, Glynn P. 1990. Oxygenation-sensitive contrast in magnetic resonance image of rodent brain at high magnetic fields. Magn. Reson. Med. 14:68-78

12. Ogawa S, Lee T-M. 1990. Magnetic resonance imaging of blood vessels at high fields: in vivo and in vitro measurements and image simulation. Magn. Reson. Med. 16:9-18

13. Fox PT, Raichle ME. 1986. Focal physiological uncoupling of cerebral blood flow and oxidative metabolism during somatosensory stimulation in human subjects. Proc. Natl. Acad. Sci. USA 83(4): 1140-44

14. Raichle ME. 1997. Food for thought. The metabolic and circulatory requirements of cognition. Ann. NY Acad. Sci. 835:37385

15. Fox PT, Raichle ME, Mintun MA, Dence C. 1988. Nonoxidative glucose consumption during focal physiologic neural activity. Science 241(4864):462-64

16. Ogawa S, Menon RS, Tank DW, Kim S-G, Merkle H, et al. 1993. Functional brain mapping by blood oxygenation leveldependent contrast magnetic resonance imaging. Biophys. J. 64:800-12

17. Kennan RP, Zhong J, Gore JC. 1994. Intravascular susceptibility contrast mechanisms in tissue. Magn. Reson. Med. 31:931

18. Weisskoff RM, Zuo CS, Boxerman JL, Rosen BR. 1994. Microscopic susceptibility variation and transverse relaxation: theory and experiment. Magn. Reson. Med. 31(6):601-10

19. Boxerman JL, Hamberg LM, Rosen BR, Weisskoff RM. 1995. MR contrast due to intravascular magnetic susceptibility perturbations. Magn. Reson. Med. 34:555-56

20. Buxton RB, Frank LR. 1997. A model 
for the coupling between cerebral blood flow and oxygen metabolism during neural stimulation. J. Cereb. Blood Flow Metab. 17(1):64-72

21. Ogawa S, Menon RS, Kim S-G, Ugurbil K. 1998. On the characteristics of functional magnetic resonance imaging of the brain. Annu. Rev. Biophys. Biomol. Struct. 27:447-74

22. van Zijl PC, Eleff SM, Ulatowski JA, Oja JM, Ulug AM, et al. 1998. Quantitative assessment of blood flow, blood volume and blood oxygenation effects in functional magnetic resonance imaging. Nat. Med. 4(2):159-67

23. Edelman RE, Siewer B, Darby DG, Thangaraj V, Nobre AC, et al. 1994. Quantitative mapping of cerebral blood flow and functional localization with echoplanar MR imaging and signal targeting with alternating radio frequency. Radiology 192:513-20

24. Kim S-G. 1995. Quantification of relative cerebral blood flow change by flowsensitive alternating inversion recovery (FAIR) technique: application to functional mapping. Magn. Reson. Med. 34: 293-301

25. Kim S-G, Tsekos NV. 1997. Perfusion imaging by a flow-sensitive alternating inversion recovery (FAIR) technique: application to functional brain imaging. Magn. Reson. Med. 37(3):425-35

26. Kim S-G, Ugurbil K. 1997. Comparison of blood oxygenation and cerebral blood flow effects in fMRI; estimation of relative oxygen consumption change. Magn. Reson. Med. 38(1):59-65

27. Wong EC, Buxton RB, Frank LR. 1998. Quantitative imaging of perfusion using a single subtraction (QUIPSS and QUIPSS II). Magn. Reson. Med. 39(5):702-8

28. Detre JA, Leigh JS, Williams DS, Koretsky AP. 1992. Perfusion imaging. Magn. Reson. Med. 23:37-45

29. Detre JA, Zhang W, Roberts DA, Silva AC, Williams DS, et al. 1994. Tissue specific perfusion imaging using arterial spin labeling. NMR Biomed. 7(1-2):75-82

30. Roberts DA, Detre JA, Bolinger L, Insko EK, Leigh JS. 1994. Quantitative magnetic resonance imaging of human brain perfusion at $1.5 \mathrm{~T}$ using steady-state inversion of arterial water. Proc. Natl. Acad. Sci. USA 91:33-37

31. Kwong KK, Chesler DA, Weisskoff RM, Donahue KM, Davis TL, et al. 1995. MR perfusion studies with T1-weighted echo planar imaging. Magn. Reson. Med. 34:878-87

32. Springer CS, Xu Y. 1991. Aspects of bulk magnetic susceptibility in in vivo MRI and MRS. In New Developments in Contrast Agent Research, ed. PA Rinck, RN Muller, pp. 13-25. Blonay, Switz: Eur. Magn. Reson. For.

33. Ugurbil K, Garwood M, Ellermann J, Hendrich K, Hinke R, et al. 1993. Imaging at high magnetic fields: initial experiences at 4 T. Magn. Reson. Q. 9(4):259-77

34. Boxerman JL, Weisskoff RM, Hoppel BE, Rosen BR. 1993. MR contrast due to microscopically heterogeneous magnetic susceptibilty: cylindrical geometry. Proc. Annu. Meet. Int. Soc. Magn. Reson. Med., 12th, New York, p. 389. Berkeley, CA: Int. Soc. Magn. Reson. Med.

35. Eichling JO, Raichle ME, Grubb RL, TerPogossian MM. 1974. Evidence of the limitations of water as a freely diffusable tracer in brain of the Rhesus monkey. Circ. Res. 35(3):358-64

36. Paulson OB, Hertz MM, Bolwig TG, Lassen NA. 1977. Water filtration and diffusion across the blood brain barrier in man. Acta Neurol. Scand. Suppl. 64:49293

37. Paulson OB, Hertz MM, Bolwig TG, Lassen NA. 1977. Filtration and diffusion of water across the blood-brain barrier in man. Microvasc. Res. 13(1):113-24

38. Mandeville JB, Marota JJ, Kosofsky BE, Keltner JR, Weissleder R, et al. 1998. Dynamic functional imaging of relative 
cerebral blood volume during rat forepaw stimulation. Magn. Reson. Med. 39(4): 615-24

39. Duong TQ, Kim S-G. 2000. Relationship between $\mathrm{CBF}$ and arterio-venous relative CBV changes during hypercapnia in rat brain-a ${ }^{19} \mathrm{~F} /{ }^{1} \mathrm{H}$ NMR study. Annu. Meet. Book Abstr. Int. Soc. Magn. Reson. Med. p. 955

40. Thulborn KR, Waterton JC, Matthews PM, Radda GK. 1982. Oxygenation dependence of the transverse relaxation time of water protons in whole blood at high field. Biochem. Biophys. Acta 714:265-70

41. Thulborn KR, Waterton JC, Matthews PM. 1992. Dependence of the transverse relaxation time of water protons in whole blood at high field. Biochem. Biophys. Acta 714:265-72

42. Barth M, Moser E. 1997. Proton NMR relaxation times of human blood samples at $1.5 \mathrm{~T}$ and implications for functional MRI. Cell. Mol. Biol. 43(5):783-91

43. Jezzard P, Duewell S, Balaban RS. 1996. MR relaxation times in human brain: measurement at 4 T. Radiology 199(3):773-79

44. Wehrli FW, MacFall JR, Schutts D, Breger R, Herfkens RJ. 1984. Mechanism of contrast in NMR. J. Comput. Assist. Tomogr. 8(3):369-80

45. Lee S-P, Silva AC, Ugurbil K, Kim S-G. 1999. Diffusion weighted spin echo fMRI at $9.4 \mathrm{~T}$ : microvascular/tissue contribution to BOLD signal changes. Mag. Reson. Med. 42(5):919-28

46. Pawlik G, Rackl A, Bing RJ. 1981. Quantitative capillary topography and blood flow in the cerebral cortex of cats: an in vivo microscopic study. Brain Res. 208(1):3558

47. Stejskal EO, Tanner JE. 1965. Spin diffusion measurements: spin-echoes in the presence of a time dependent field gradient. J. Chem. Phys. 42:288-92

48. Ugurbil K, Ogawa S, Kim S-G, Hu X, Chen W, Zhu X-H. 1999. Imaging brain activity using nuclear spins. In Magnetic
Resonance and Brain Function, ed. B Maraviglia, pp. 261-301. Amsterdam, Netherlands: IOS Press

49. Boxerman JL, Bandettini PA, Kwong KK, Baker JR, Davis TL, et al. 1995. The intravascular contribution to fMRI signal change: Monte Carlo modeling and diffusion-weighted studies in vivo. Magn. Reson. Med. 34(1):4-10

50. Song AW, Wong EC, Tan SG, Hyde JS. 1996. Diffusion weighted fMRI at $1.5 \mathrm{~T}$. Magn. Reson. Med. 35(2):155-58

51. Henkelman RM, Neil JJ, Xiang QS. 1994. A quantitative interpretation of IVIM measurements of vascular perfusion in the rat brain. Magn. Reson. Med. 32(4):464-69

52. Haacke EM, Hopkins A, Lai S, Buckley P, Friedman L, et al. 1994. 2D and 3D high resolution gradient echo functional imaging of the brain: venous contributions to signal in motor cortex studies. NMR Biomed. 7(1-2):54-62. Erratum. 1994. NMR Biomed. 7(8):374

53. Menon RS, Hu X, Adriany G, Andersen P, Ogawa S, Ugurbil K. 1994. Comparison of SE-EPI, ASE-EPI and conventional EPI applied to functional neuroimaging: the effect of flow crushing gradients on the BOLD signal. Proc. Soc. Magn. Reson., San Francisco, 2:622

54. Ugurbil K, Hu X, Chen W, Zhu X-H, Kim S-G, Georgopoulos A. 1999. Functional mapping in the human brain using high magnetic fields. Philos. Trans. R. Soc. London Ser. B 354:1195-213

55. Frostig RD, Lieke EE, Ts'o DY, Grinvald A. 1990. Cortical functional architecture and local coupling between neuronal activity and the microcirculation revealed by in vivo high-resolution optical imaging of intrinsic signals. Proc. Natl. Acad. Sci. USA 87(16):6082-86

56. Malonek D, Grinvald A. 1996. Interactions between electrical activity and cortical microcirculation revealed by imaging spectroscopy: implication for functional brain mapping. Science 272:551-54 
57. Grinvald A, Slovin H, Vanzetta I. 2000. Non-invasive visualization of cortical columns by fMRI. Nat. Neurosci. 3:105-7

58. Vanzetta I, Grinvald A. 1999. Increased cortical oxidative metabolism due to sensory stimulation: implications for functional brain imaging. Science 286(5444): 1555-58

59. Budinger TF, Budinger MD. 1999. Physiological changes in brain microcirculation during activation. In Magnetic Resonance and Brain Function, ed. B Maraviglia, pp. 395-410. Amsterdam, Netherlands: IOS Press

60. Ernst T, Hennig J. 1994. Observation of a fast response in functional MR. Magn. Reson. Med. 32:146-49

61. Menon RS, Ogawa S, Hu X, Strupp JP, Anderson P, Ugurbil K. 1995. Bold based functional MRI at 4 Tesla includes a capillary bed contribution: echo-planar imaging correlates with previous optical imaging using intrinsic signals. Magn. Reson. Med. 33(3):453-59

62. Le TH, Hu X. 1996. Evaluation of the early response in fMRI in individual subjects using short stimulus duration. Proc. Annu. Meet. Int. Soc. Magn. Reson. Med. Berkeley, CA: Int. Soc. Magn. Reson. Med.

63. McIntosh J, Zhang Y, Kidambi S, Harshbarger T, Mason G. et al. 1996. Echo time dependence of functional MRI fast response. Proc. Int. Soc. Magn. Reson. Med., 1:284. Berkeley, CA: Int. Soc. Magn. Reson. Med.

64. Hu X, Le TH, Ugurbil K. 1997. Evaluation of the early response in fMRI using short stimulus duration. Magn. Reson. Med. 37:877-84

65. Moore GG, Zhang YT, Twieg DB. 1997. Assessment of the fast response spatial distribution. Proc. Int. Soc. Magn. Reson. Med. Sci. Meet. Exhib., 5th, Vancouver, B. C., Can., 1:377. Berkeley, CA: Int. Soc. Magn. Reson. Med.

66. Twieg DB, Moore GG, Zhang YT. 1997. Estimating fast response onset time. Proc.
Int. Soc. Magn. Reson. Med. Sci. Meet. Exhib., 5th, Vancouver, B.C., Can., p. 1645. Berkeley, CA: Int. Soc. Magn. Reson. Med. 67. Yacoub E, Le TH, Ugurbil K, Hu X. 1999. Further evaluation of the initial negative response in functional magnetic resonance imaging. Magn. Reson. Med.41(3):436-41

68. Yacoub E, Vaughan T, Adriany G, Andersen P, Merkle H, et al. 2000. Observation of the initial "dip" in fMRI signal in human visual cortex at 7 Tesla. Proc. Int. Soc. Magn. Reson. Med., Philadelphia, PA. 8:991. Berkeley, CA: Int. Soc. Magn. Reson. Med.

69. Logothetis NK, Gugenberger H, Peled S, Pauls J. 1999. Functional imaging of the monkey brain. Nat. Neurosci. 2(6):555-60

70. Frahm J, Kruger KD, Merboldt KD, Kleinschmidt A. 1996. Dynamic uncoupling and recoupling of perfusion and oxidative metabolism during focal brain activation in man. Magn. Reson. Med. 35:143-48

71. Brodmann K. 1909. Lokalisationslehre der Grosshirnrinde. Leipzig, Ger.: Verlag von Johann Ambrosius Barth

72. Hubel DH, Wiesel TN. 1962. Receptive field, binocular interactions and functional architecture in the cat's visual cortex. $J$. Physiol. 160:106-54

73. LeVay S, Stryker MP, Shatz CJ. 1978. Ocular dominance columns and their development in layer IV of the cat's visual cortex: a quantitative study. J. Comp. Neurol. 179(1):223-44

74. LeVay S, Nelson SB. 1991. Vision and Visual Dysfunction, pp. 266-315. Houndsmill: Macmillan

75. Engel SA, Glover GH, Wandell BA. 1997. Retinotopic organization in human visual cortex and the spatial precision of functional MRI. Cereb. Cortex 7(2):181-92

76. Lowel S, Freeman B, Singer W. 1987. Topographic organization of the orientation column system in large flat-mounts of the cat visual cortex: a 2-deoxyglucose study. J. Comp. Neurol. 255(3):401-15

77. Bonhoeffer T, Grinvald A. 1991. Iso- 
orientation domains in cat visual cortex are arranged in pinwheel-like patterns. Nature 353(6343):429-31

78. Kim DS, Bonhoeffer T. 1994. Reverse occlusion leads to a precise restoration of orientation preference maps in visual cortex. Nature 370(6488):370-72. Erratum. 1994. Nature 372(6502):196

79. Swindale NV, Matsubara JA, Cynader MS. 1987. Surface organization of orientation and direction selectivity in cat area $18 . J$. Neurosci. 7(5):1414-27

80. Shmuel A, Grinvald A. 1996. Functional organization for direction of motion and its relationship to orientation maps in cat area 18. J. Neurosci. 16(21):6945-64

81. Maldonado PE, Godecke I, Gray CM, Bonhoeffer T. 1997. Orientation selectivity in pinwheel centers in cat striate cortex. Science 276(5318):1551-55

82. Crair MC, Gillespie DC, Stryker MP. 1998. The role of visual experience in the development of columns in cat visual cortex. Science 279(5350):566-70

83. Horton JC, Hedley-White ET. 1984. Mapping of cytochrome oxidase patches and ocular dominance columns in human visual cortex. Philos. Trans. R. Soc. London Ser. B 304:255-72

84. Horton JC, Dagi LR, McCrane EP. 1990. Arrangement of ocular dominance columns in human visual cortex. Arch. Opthalmol. 108:1025-31

85. Kennedy C, Des Rosiers MH, Sakurada O. 1976. Metabolic maps of the primary visual system of the monkey by means of autoradiographic ${ }^{14} \mathrm{C}$-deoxyglucose technique. Proc. Natl. Acad. Sci. USA 73:423034

86. Hubel DH, Wiesel TN. 1977. Functional architecture of macaque monkey visual cortex. Proc. R. Soc. London Ser. B 198:1-59

87. LeVay S, Connolly M, Houde J. 1985. The complete pattern of ocular dominance stripes in the striate cortex and visual field of the macaque monkey. J. Neurosci. 5:486-501
88. Grinvald A, Lieke E, Frostig RD, Gilbert CD, Wiesel TN. 1986. Functional architecture of cortex revealed by optical imaging of intrinsic signals. Nature 324(6095):36164

89. Ts'o DY, Frostig RD, Lieke EE, Grinvald A. 1990. Functional organization of primate visual cortex revealed by high resolution optical imaging. Science 249(4967):417-20

90. Grinvald A, Frostig RD, Siegel RM, Bartfeld E. 1991. High-resolution optical imaging of functional brain architecture in the awake monkey. Proc. Natl. Acad. Sci. USA 88(24):11559-63

91. Gati JS, Menon RS, Ugurbil K, Rutt BK. 1997. Experimental determination of the BOLD field strength dependence in vessels and tissue. Magn. Reson. Med. 38(2):296302

92. Menon RS, Ogawa S, Strupp JP, Ugurbil K. 1997. Ocular dominance in human V1 demonstrated by functional magnetic resonance imaging. J. Neurophysiol. 77(5):2780-87

93. Menon RS, Goodyear BG. 1999. Submillimeter functional localization in human striate cortex using BOLD contrast at 4 Tesla: implications for the vascular point-spread function. Magn. Reson. Med. 41(2):230-35

94. Menon RS, Kim S-G. 1999. Spatial and temporal limits in cognitive neuroimaging with fMRI. Trends Cogn. Neurosci. 3(6):207-16

95. Menon RS, Ogawa S, Ugurbil K. 1996. Mapping ocular dominance columns in human V1 using fMRI. NeuroImage 3:S357

96. Blamire AM, Ogawa S, Ugurbil K, Rothman D, McCarthy G, et al. 1992. Dynamic mapping of the human visual cortex by high-speed magnetic resonance imaging. Proc. Natl. Acad. Sci. USA 89:11069-73

97. Savoy RL, Bandettini PA, O'Craven KM, Kwong KK, Davis TL, et al. 1995. Pushing the temporal resolution of fMRI: studies of very brief visual stimuli, onset variability 
and asynchrony, and stimulus-correlated changes in noise. Proc. Sci. Meet. Soc. Magn. Reson. Med., 3rd, Nice, Fr., p. 450.

98. Kim S-G, Richter W, Ugurbil K. 1997. Limitations of temporal resolution in functional MRI. Magn. Reson. Med. 37(4):631-36

99. Richter W, Andersen PM, Georgopoulos AP, Kim S-G. 1997. Sequential activity in human motor areas during a delayed cued finger movement task studied by timeresolved fMRI. NeuroReport 8:1257-61

100. Richter W, Ugurbil K, Georgopoulos AP, Kim S-G. 1997. Time-resolved fMRI of mental rotation. NeuroReport 8:3697702

101. Menon RS, Luknowsky DC, Gati JS. 1998. Mental chronometry using latencyresolved functional MRI. Proc. Natl. Acad. Sci. USA 95(18):10902-7

102. Buckner RL, Bandettini PA, O'Craven KM, Savoy RL, Petersen SE. 1996. Detection of cortical activation during averaged single trials of a cognitive task using functional magnetic resonance imaging. Proc. Natl.Acad. Sci. USA 93(25):1487883

103. Kim S-G, Richter W. 1996. Limitations of temporal resolution in fMRI. In Proc. Ann. Meet. Int. Soc. Magn. Reson. Med., 1:286. Berkeley, CA: Int. Soc. Magn. Reson. Med.

104. Richter W, Kim S-G. 1996. Temporally Resolved Human Brain Activity of Delayed Cued Finger Movements Studied by fMRI, 1:22. Washington, DC: Soc. Neurosci.

105. Richter W, Ugurbil K, Kim S-G. 1996. Limitation of temporal resolution in fMRI. NeuroImage 3:S38

106. Richter W, Georgopoulos AP, Ugurbil K, Kim S-G. 1997. Detection of brain activity during mental rotation in a single trial by fMRI. In Proc. Int. Soc. Magn. Reson. Med., 1:357. Berkeley, CA: Int. Soc. Magn. Reson. Med.

107. Hu X, Kim S-G. 1994. Reduction of physiological noise in functional MRI using navigator echo. Magn. Reson. Med. 31:495-503

108. Hyde JS, Biswal B, Song AW, Tan SG. 1994. Physiological and instrumental fluctuations in fMRI data. Presented at Annu. Midwest Funct. MRI Workshop, 2nd, Madison, WI

109. Hu X, Le TH, Parrish T, Erhard P. 1995. Retrospective estimation and correction of physiological fluctuation in functional MRI. Magn. Reson. Med. 34(2):201-12

110. Mitra PP, Thompson DJ, Ogawa S, Hu X, Ugurbil K. 1995. Spatio-temporal patterns in fMRI data revealed by principal component analysis and subsequent low pass filtering. Presented at Sci. Meet. Soc. Magn. Reson, 3rd, Nice, Fr.

111. Biswal B, DeYoe EA, Hyde JS. 1996. Reduction of physiological fluctuations in fMRI using digital filters. Magn. Reson. Med. 35:117-23

112. Mitra PP, Ogawa S, Hu X, Ugurbil K. 1997. The nature of spatio-temporal changes in cerebral hemodynamics as manifested in functional magnetic resonance imaging. Magn. Reson. Med. 37(4):511-18

113. Biswal B, Yetkin FZ, Haughton VM, Hyde JS. 1995. Functional connectivity in the motor cortex of resting human brain using echo-planar MRI. Magn. Reson. Med. 34(4):537-41

114. Ogawa S, Mitra PP, Hu X, Ugurbil K. 1996. Spatio-temporal patterns revealed in denoised fMRI data: visualization of information processing in the human brain. EEG Suppl. 47:5-14

115. Biswal B, Hudetz A, Yetkin F, Haughton VM, Hyde JS. 1997. Hypercapnia reversibly suppresses low-frequency fluctuations in the human motor cortex during rest using echo-planar MRI. J. Cereb. Blood Flow Metab. 17(3):301-8

116. Gruetter R, Novotny EJ, Boulware SD, Mason GF, Rothman DL, et al. 1994. Localized ${ }^{13} \mathrm{C}$ NMR spectroscopy of amino 
acid labeling from $\left[{ }^{1-13} \mathrm{C}\right] \mathrm{D}$-glucose in the human brain. J. Neurochem. 63:137785

117. Hyder F, Chase JR, Behar KL, Mason GF, Siddeek M, et al. 1996. Increased tricarboxylic acid cycle flux in rat brain during forepaw stimulation detected with ${ }^{1} \mathrm{H}\left[{ }^{13} \mathrm{C}\right]$ NMR. Proc. Natl. Acad. Sci. USA 93(15):7612-17

118. Hyder F, Rothman DL, Mason GF, Rangarajan A, Behar KL, Shulman RG. 1997. Oxidative glucose metabolism in rat brain during single forepaw stimulation: a spatially localized ${ }^{1} \mathrm{H}\left[{ }^{13} \mathrm{C}\right]$ nuclear magnetic resonance study. J. Cereb. Blood Flow Metab. 17(10):1040-47

119. Sibson NR, Dhankhar A, Mason GF, Behar KL, Rothman DL, Shulman RG. 1997. In vivo ${ }^{13} \mathrm{C}$ NMR measurements of cerebral glutamine synthesis as evidence for glutamate-glutamine cycling. Proc. Natl. Acad. Sci. USA 94:2699704

120. Gruetter R, Seaquist ER, Kim S, Ugurbil K. 1998. Localized in vivo ${ }^{13} \mathrm{C}$ NMR of glutamate metabolism in the human brain: initial results at 4 Tesla. Dev. Neurosci. 20(4-5):380-88

121. Shen J, Petersen KF, Behar KL, Brown P, Nixon TW, et al. 1999. Determination of the rate of the glutamate/glutamine cycle in the human brain by in vivo ${ }^{13} \mathrm{C}$ NMR. Proc. Natl. Acad. Sci. USA 96(14):823540

122. Chen W, Gruetter R, Zhu X-H, Seaquist B, Ugurbil K. 2000. Study of oxygen utilization changes in human visual cortex during hemifield stimulation using ${ }^{1} \mathrm{H}-\left({ }^{13} \mathrm{C}\right)$ MRS and fMRI. Proc. Int. Soc. Magn. Reson. Med. p. 438

123. Ugurbil K, Brown TR, den Hollander JA, Glynn P, Shulman RG. 1978. Highresolution ${ }^{13} \mathrm{C}$ nuclear magnetic resonance studies of glucose metabolism in Escherichia coli. Proc. Natl. Acad. Sci. USA 75(8):3742-46

124. Gruetter R. 1993. Automatic, localized in vivo adjustment of all first- and second- order shim coils. Magn. Reson. Med. 29(6):804-11

125. Gruetter R, Adriany G, Merkle H, Andersen PM. 1996. Broadband decoupled, ${ }^{1} \mathrm{H}-$ localized ${ }^{13} \mathrm{C}$ MRS of the human brain at 4 tesla. Magn. Reson. Med. 36(1):659-64

126. Adriany G, Gruetter R. 1997. A half volume coil for efficient proton decoupling in humans at 4 Tesla. J. Magn. Reson. 125:178-84

127. Pfeuffer J, Tkac I, Choi IY, Merkle H, Ugurbil K, et al. 1999. Localized in vivo ${ }^{1} \mathrm{H}$ NMR detection of neurotransmitter labeling in rat brain during infusion of $\left[{ }^{1-13} \mathrm{C}\right]$ D-glucose. Magn. Reson. Med. 41(6):1077-83

128. Bergles DE, Dzubay JA, Jahr CE. 1997. Glutamate transporter currents in bergmann glial cells follow the time course of extrasynaptic glutamate. Proc. Natl. Acad. Sci. USA 94(26):14821-25

129. Bergles DE, Diamond JS, Jahr CE. 1999. Clearance of glutamate inside the synapse and beyond. Curr. Opin. Neurobiol. 9(3):293-98

130. Martinez-Hernandez A, Bell KP, Norenberg MD. 1976. Glutamine synthetase: glial localization in brain. Science 195: 1356-58

131. Gruetter R, Novotny EJ, Boulware SD, Rothman DL, Mason GF, et al. 1992. Direct measurement of brain glucose concentrations in humans by ${ }^{13} \mathrm{C}$ NMR spectroscopy. Proc. Natl. Acad. Sci. USA 89(3):1109-12. Erratum. 1992. Proc. Natl. Acad. Sci. USA 89(24):12208

132. Gruetter R, Ugurbil K, Seaquist ER. 1998. Steady-state cerebral glucose concentrations and transport in the human brain. $J$. Neurochem. 70(1):397-408

133. Gruetter R, Weisdorf SA, Rajanayagan V, Terpstra M, Merkle H, et al. 1998. Resolution improvements in in vivo ${ }^{1} \mathrm{H}$ NMR spectra with increased magnetic field strength. J. Magn. Reson. 135(1):260-64

134. Siesjo B. 1978. Brain Energy Metabolism, pp. 101-10. New York: Wiley \& Sons 